Board of Governors of the Federal Reserve System

International Finance Discussion Papers

Number 1317

April 2021

\title{
The Global Transmission of Real Economic Uncertainty
}

Juan M. Londono, Sai Ma, and Beth Anne Wilson

Please cite this paper as:

Londono, Juan M., Sai Ma, and Beth Anne Wilson (2021). "The Global Transmission of Real

Economic Uncertainty," International Finance Discussion Papers 1317. Washington: Board

of Governors of the Federal Reserve System, https://doi.org/10.17016/IFDP.2021.1317.

NOTE: International Finance Discussion Papers (IFDPs) are preliminary materials circulated to stimulate discussion and critical comment. The analysis and conclusions set forth are those of the authors and do not indicate concurrence by other members of the research staff or the Board of Governors. References in publications to the International Finance Discussion Papers Series (other than acknowledgement) should be cleared with the author(s) to protect the tentative character of these papers. Recent IFDPs are available on the Web at www.federalreserve.gov/pubs/ifdp/. This paper can be downloaded without charge from the Social Science Research Network electronic library at www.ssrn.com. 


\title{
The Global Transmission of Real Economic Uncertainty*
}

\author{
Juan M. Londono, Sai Ma \\ Federal Reserve Board, Division of International Finance \\ Preliminary draft \\ This Version: April 23, 2021
}

\begin{abstract}
Using a sample of 30 countries representing about $65 \%$ of the global GDP, we find that real economic uncertainty (REU) has negative long-lasting domestic economic effects and transmits across countries. The international spillover effects of REU are (i) additional to those of domestic REUs, (ii) statistically significant, and (iii) economically meaningful. Trade ties play a key role in explaining why uncertainty generated in one country can affect economic outcomes in other countries. Based on this evidence, we construct a novel index for global REU as the trade-weighted average of all countries' REUs. We disentangle the effects of the domestic and foreign components of global REU and find that, on average, innovations to the foreign component can contribute up to $28 \%$ of the future variation in domestic industrial production, with the effect being disproportionately larger on its manufacturing component, the component contributing the most to the tradable goods sector, than on its retail sales component.
\end{abstract}

JEL Classification: E32, F44, F62, G01

Keywords: Economic effects of uncertainty, International transmission, Spillovers

${ }^{*}$ We have benefited greatly from comments and suggestions by Sydney Ludvigson, Serena Ng, and Frank Warnock. We would also like to thank seminar participants at the Federal Reserve Board. The analysis and conclusions set forth are those of the authors and do not indicate concurrence by other members of the research staff or the Board of Governors.

${ }^{\dagger}$ Corresponding author. E-mail: sai.ma@frb.gov 


\section{Introduction}

Uncertainty about international economic conditions is frequently mentioned as a risk, a cross current, or a headwind to domestic economic outlooks 1 However, although recent literature hints at various sources of global financial risk (see, e.g., Miranda-Agrippino and Rey (2018) and $\mathrm{Xu}(2019)$ ), there is little evidence quantifying the impact of real economic uncertainty for countries other than the United States and documenting the transmission of economic uncertainty across countries. To bridge this gap in the literature, in this paper, we construct econometric-based measures of real economic uncertainty (REU hereafter), which are based on the predictability of near-term economic performance (Jurado et al. (2015), hereafter JLN), for a sample of 30 countries representing over 65 percent of global GDP. We find that REU has significant and economically meaningful domestic and spillover effects for real activity indicators. We also provide an economic explanation for the transmission of REU across countries by showing that trade ties among countries are the main driver of the spillovers of REU. Based on this evidence, we construct a novel measure of global REU as the trade-weighted average of all countries' REUs. Our results provide evidence for the global nature of REU and for its transmission across countries through real economic channels.

We calculate REU measures for 30 countries, including advanced and emerging market economies, using a large set of economic and financial time series starting as early as 1960 for most countries in our sample. We use the same source to obtain economic series for all countries, the monthly OECD main economic indicators (MEI), in an effort to achieve the consistency and comparability of our measure across countries. We find that REU measures are highly correlated across countries - the mean correlation across all countries' REUs is $25 \%$. In particular, REU measures in all countries increase sharply around global recessions, such as the 2008 Global Financial Crisis (GFC) and, more recently, the COVID-19 crisis in 2020. In fact, all but six countries in our sample experienced the largest REU realizations in the first semester of 2020 . However, there is substantial heterogeneity in the dynamics of REUs across countries suggesting that REU is also driven by country or region-specific events, such as the euro-area crisis and the Brexit referendum.

To validate our REU measures, in the first part of the paper, we extend the evidence in Jurado et al. (2015) for the United States to all countries in our sample by relating REU with domestic economic activity, measured by each country's industrial production (IP), in a vector-autoregressive (VAR) framework. We find evidence that an increase in domestic uncertainty is associated with an economically meaningful decline in domestic real activity-

\footnotetext{
${ }^{1}$ Federal Reserve Board's Chair Janet Yellen press conference after the September of 2015 FOMC meeting is a fine example of this: https://www.federalreserve.gov/mediacenter/files/ fomcpresconf20150917.pdf.
} 
a four-standard deviation increase in domestic REU, which is similar to that experienced around the collapse of Lehman Brothers in 2008, is followed by drops in domestic output between $1.6 \%$ and $8.4 \%$, depending on the country. Our findings of significant domestic economic effects of REU remain qualitatively robust to alternative VAR lags, to alternative orderings of the variables in the VAR system, even if REU is ordered last, and to alternative control variables.

To what extent can macroeconomic uncertainty generated in one country not only be related to domestic economic outcomes but also affect outcomes in other countries? The intuition in the existing literature comes exclusively from domestic general equilibrium settings; for instance, fixed costs or financial constraints (see JLN and papers cited therein). In the second part of the paper, we explore the cross-country spillover effects of REU using an extended version of our VAR framework including domestic and foreign economic activity measures and REUs. To aggregate the effects of foreign REU, we initially consider a foreign REU measure calculated as an equally-weighted average of all other countries' REUs. We show that the domestic economic effects of foreign REU are also significant and economically meaningful; an increase in economic uncertainty generated in other countries is also followed by a decrease in domestic economic activity. Moreover, the dynamic correlation between domestic economic activity indicators and foreign macroeconomic uncertainty are, for most countries in our sample, of a similar or larger magnitude than those of domestic uncertainty - a four-standard deviation increase in foreign REU is followed by a maximum drop in domestic IP within the 60-month horizon between 2 percent (Australia and the United Kingdom) and 8 percent (Slovenia).

A natural question is: why should an increase in foreign economic uncertainty also imply a reduction in domestic economic activity? We address this question in the third part of the paper by exploring the possible economic drivers of the transmission of REU across countries. We propose conditional and unconditional settings relating the effects of REU generated in any country on any other country's economic activity with measures of trade and financial ties between any two countries. We find that trade ties, which are measured for each country as the ratio of total trade volume to another country to domestic GDP, play a key role at explaining the cross-country economic spillover effects of REU. Financial ties, measured as the ratio of total assets and liabilities owned and owed by foreigners in another country to domestic GDP, do not significantly explain the transmission of foreign REU. Our evidence then suggests that macroeconomic uncertainty transmits to other countries mostly through trade channels.

Motivated by the evidence for the key role of trade ties in explaining the transmission of REU across countries, we propose a new measure of global REU, which is calculated as a 
trade-weighted average of REU across all countries. We find that our global REU index has significant and economically meaningful effects for industrial production for all countries in our sample. We disentangle the domestic and foreign (trade-weighted average for all other countries) components of global REU and find that, on average, innovations to the foreign component of global REU contribute up to $28 \%$ of the variation in domestic industrial production across the 30 countries in our sample. More importantly, for most countries, the effect of the foreign component of global REU on domestic IP is stronger than that of domestic REU itself - domestic REU contributes, on average, up to $19 \%$ of the variation in domestic industrial production. To explore further the transmission channel of REU across countries, we disentangle the effect of global REU separately on the manufacturing and retail service components of industrial production. The foreign component of global REU has a much larger effect on the manufacturing sector, one of the largest component of the tradeable goods sector for all countries, while the effect on the retail sales sector, which is naturally less exposed to trade, is smaller and often statistically insignificant.

Our paper relates closely to the recent growing body of empirical studies on the real effect of uncertainty. Angelini et al. (2019) and Carriero et al. (2018) find that macroeconomic uncertainty in the United States has a strong negative effect on domestic real activities. Using a shock-restricted SVAR approach, Ludvigson et al. (2020a) finds that uncertainty about financial market outcomes is a possible source of U.S. business cycle fluctuations. Several other papers document that higher uncertainty about future economic conditions has a contractionary impact on U.S. economic growth, including Baker and Bloom (2013), Caldara et al. (2016), Alfaro et al. (2016), and Shin and Zhong (2018). However, studies on the transmission of global economic uncertainty and on its impact on economic indicators for countries other than the United States are still rather limited or focus only on a few countries or around specific historical events, as in Cross et al. (2018) and Balcilar et al. (2020). We contribute to this literature by estimating measures of REU for a large set of countries and by using this large panel dataset to document the cross-country economic spillovers of REU.

There are two important challenges when studying the effects of uncertainty for a large sample of countries. First, it is challenging to construct an objective measure of uncertainty about underlying economic fundamentals. Textual-based uncertainty measures, such as global policy economic uncertainty (EPU) from Baker et al. (2016), constructed by counting the number of articles in leading newspapers that contain uncertainty-related words; survey-based uncertainty measures, in, e.g., Altig, Barrero, Bloom, Davis, Meyer, and Parker (2020) and Leduc and Liu (2016); and asset-based uncertainty measures, such as realized and option-implied volatility, might reflect the perception of particular segments of the population (news editors, survey respondents, and market participants in a particular asset, 
respectively) and do not necessarily reflect uncertainties driven by underlying macroeconomic activities $2^{2}$ To address this issue, we follow the methodology proposed by Jurado et al. (2015) for the United States and extend it to a sample of 30 countries over a long time series starting in the early 1960s. JLN's uncertainty index is constructed as an aggregate of the volatility of statistical forecasts for a large number of economic series and, hence, reflects the objective uncertainty on aggregate economic activities. Several studies have explored measures of global and country-specific uncertainties, including Davis (2016), Ozturk and Sheng (2018), and Cesa-Bianchi et al. (2020). However, these papers focus on financial or political uncertainties, while we contribute to this literature by exclusively focusing on the uncertainty about future real economic conditions and its transmission across countries.

The second challenge is building REU measures that are consistent and comparable across countries. To tackle this challenge, we use the monthly OECD main economic indicators (MEI) as the data source for all underlying economic series when constructing REUs for all countries. These measures are comparable across countries and allow us to explore the international spillovers and study the fundamental explanation of the transmission of global uncertainty. This paper is, to the best of our knowledge, the first one to propose a consistent methodology to study the transmission of real economic uncertainty across a large sample of countries. We contribute to a limited number of studies on the international transmission of uncertainty. Bhattarai et al. (2019) studies the global spillover effects of U.S. uncertainty, and Londono et al. (2019) finds empirical evidence that foreign uncertainty measures from G7 countries have a negative impact on U.S. industrial production. However, all these papers focus almost exclusively on the United States as the country either generating uncertainty or being affected by it; while we study the relation between economic uncertainty generated in any country in our sample and its potential effects on economic activity indicators in any other country.

Finally, our paper also contributes to the literature documenting the role of international integration at explaining the transmission of shocks across countries (see, for instance, Londono and Xu (2020); Bowman et al. (2015); and Kose et al. (2009)). This literature has mostly focused on the transmission of financial shocks, while we explore the fundamental determinants of the transmission of macroeconomic uncertainty across countries and document that real uncertainty transmit mostly through the trade channel.

The remainder of the paper is organized as follows. Section 2 explains the method used to calculate REUs for all countries in our sample. Section 3 documents the domestic and spillover effects of REU. Section 4 proposes a measure of global economic uncertainty and

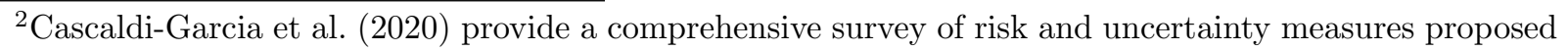
in the literature and provide a discussion for the differences across measures. 
studies its impact on domestic IPs and its manufacturing and retail sales sectors. Concluding remarks are included in Section 5 .

\section{A measure of real economic uncertainty}

In this section, we explain the method used to calculate the real economic uncertainty (REU) index for each country. We then introduce the data used to calculate the REU indexes and analyze their dynamics.

\subsection{The REU index}

Following the methodology in $\mathrm{JLN}$, for each country $j, R E U_{j t}$ aggregates the metrics of uncertainty constructed for a large number of individual macroeconomic data series denoted by $Y_{j, t}$. For each macroeconomic series in this set, $y_{j, t} \in Y_{j, t}$, the $h$-period ahead uncertainty, denoted by $\mathcal{U}_{j, t}(h)$, is defined to be the volatility of the purely unforecastable component of the future value of the series, conditional on all information available. Specifically,

$$
\mathcal{U}_{j, t}(h) \equiv \sqrt{\mathbb{E}\left[\left(y_{j, t+h}-\mathbb{E}\left[y_{j, t+h} \mid I_{j, t}\right]\right)^{2} \mid I_{j, t}\right]},
$$

where $I_{j, t}$ denotes the information available up to time $t$ for country $j$. Then, the $h$-period REU index is calculated as an aggregate of individual uncertainty measures across all economic series, as follows:

$$
R E U_{j, t}(h) \equiv \operatorname{plim}_{N_{j} \rightarrow \infty} \frac{1}{N_{j}} \sum_{i=1}^{N_{j}} \mathcal{U}_{j, t}(h) \equiv \mathbb{E}\left[\mathcal{U}_{j, t}(h)\right]
$$

where $N_{j}=\operatorname{dim}\left(Y_{j, t}\right)$ is the number of series in $Y_{j, t}$. The conditional expectation of the squared forecast errors, $\left(y_{j, t+h}-\mathbb{E}\left[y_{j, t+h} \mid I_{j, t}\right]\right)^{2}$ in Equation (1), is computed from a stochastic volatility model where the log volatility of the series $y_{j, t}$ is assumed to be time-varying and to follow an autoregressive model ${ }^{3}$ The assumption of stochastic volatility is crucial, as it permits the construction of a second-moment shock that is orthogonal to the innovation to the level of $y_{j, t}$. In addition, each economic time series $y_{j, t}$ is assumed to be stationary and

\footnotetext{
${ }^{3}$ The $\log$ volatility of $y_{j, t+h}$ follows the process

$$
\log \left(\sigma_{j t+1}^{y}\right)^{2}=\alpha_{j}^{y}+\beta_{j}^{y} \log \left(\sigma_{j t}^{y}\right)^{2}+\tau_{j}^{y} \eta_{j t+1} .
$$

The stochastic volatility parameters, $\alpha_{j}^{y}, \beta_{j}^{y}$, and $\tau_{j}^{y}$, are estimated from least square residuals of the forecasting models using Markov chain Monte Carlo (MCMC) methods.
} 
to have a factor structure that takes the following form:

$$
y_{j, t}=\Lambda_{j}^{F^{\prime}} \mathbf{F}_{j t}+e_{j t}
$$

where $\mathbf{F}_{j t}$ in country $j$ is a $N_{j F} \times 1$ vector of latent common factors, which are constructed as the static principal components from a large number of domestic real economic indicators 4 We also allow for nonlinearities by including polynomial terms in the factors and form factors estimated from squares of these factors. The estimate of the conditional expectation $\mathbb{E}\left[y_{j, t+h} \mid I_{t}\right]$ in Equation (1) is then obtained by the forecast of $y_{j, t+h}$ using all these factors. The use of large datasets in each country is important to reduce the biases when relevant predictive information is neglected. Intuitively, our REU measure focuses on whether a country's economy has become more or less predictable month to month; that is, on how accurately we can anticipate economic conditions in the near future based on what we know now. The less easy the economy is to predict, the more real economic uncertainty there is.

\subsection{Data and dynamics of international REUs}

We calculate the monthly REU index for the following 30 countries: Australia, Austria, Belgium, Brazil, Canada, Denmark, Finland, France, Germany, Greece, Iceland, Ireland, Israel, Italy, Japan, Korea, Luxembourg, Mexico, the Netherlands, New Zealand, Norway, Poland, Portugal, Slovenia, Spain, Sweden, Switzerland, Turkey, the United Kingdom, the United States. These 30 countries represent about $65 \%$ of the world GDP in 2019.5

The use of large financial and economic data sets is important to reduce the possibility of biases that arise when relevant predictive information for $y_{j, t}$ is ignored. Therefore, our vector of macroeconomic series in $Y_{j, t}$ includes a broad range of indicators of the real economy for each country (between 30 to 100 indicators depending on the country). These indicators include monthly series for output, sales and orders, prices, labor market activity, trade, monetary instruments, consumer and business confidence, and residential and nonresidential investment. To better ensure the consistency and cross-country comparability of our data, we use the monthly OECD main economic indicators (MEI) as the single source for all economic series. ${ }^{6}$

To construct the diffusion index forecast $\mathbb{E}\left[y_{j, t+h} \mid I_{t}\right]$ for each economic series, in addition to the economic series in $Y_{j, t}$, we further include 247 monthly global financial series to the information set $I_{j, t}$. This extended set of predictors is meant to capture the relevant

\footnotetext{
${ }^{4}$ The number of factors $N_{j F}$ is determined by the criterion of Bai and $\mathrm{Ng}(2002)$.

${ }^{5}$ Using GDP series in U.S. dollars at 2019Q4 prices and exchange rates. Source: Haver Analytics.

${ }^{6}$ It is worth noting that many of the economic indicators are not stationary. Because the estimates of the stochastic volatility process and factors require that all series should be stationary, we follow JLN and transform each indicator using first or second differences before the estimation of REUs.
} 
information contained in global financial markets when forecasting economic series. These financial series include valuation ratios, such as the dividend- and earning-price ratios, yields on corporate bonds of different rating grades, yields on Treasuries and yield spreads, and a broad cross section of international equity index portfolios:7

The sample period used to calculate REU indexes varies across countries, depending on the availability of the variables used to calculate the index. Table 1 shows the total number of underlying economic series used to calculate the REU index and the dates for which the index is available for each country in our sample. For most of the countries (28 out of 30), our monthly sample starts as early as in the 1960s and all series are available up to April 2020. The use of long time series allows us to cover both global as well as country-specific events featuring large swings of economic uncertainties in all countries.

$$
\text { [Table } 1 \text { here] }
$$

Figure 1 shows the time series of REU for all countries in our sample and Table 2 shows a set of summary statistics for these time series. Historical mean REU ranges from 0.48 for New Zealand to 0.81 for Japan, and its standard deviation ranges from 0.06 for Australia and the United States and 0.33 for Slovenia. Uncertainty about the real economy tends to increase around global recessions, such as the 2008 Global Financial Crisis (GFC) and, more recently, the COVID-19 crisis in 2020. Not surprisingly, the maximum value of REU occurs during 2020 for all but 6 countries in our sample. REUs exceed 5 standard deviations above their historical means in April 2020 in 22 out of the 30 countries.

$$
\text { [Table } 2 \text { here] }
$$

Impact of the COVID-19 Pandemic. The outbreak of COVID-19 has significantly disrupted the economies around the globe. Ludvigson et al. (2020b) and Barrero and Bloom (2020) document that U.S. economic uncertainty rose sharply in early 2020 during the COVID-19 pandemic. We find similar evidence for other countries from our REU measures. Table 3 reports the increase in REUs from December 2019 to April 2020 and thus isolates the impact of COVID-19 on real economic uncertainties for all countries in the sample. On average, we find that REUs increased by $46 \%$ in response to the pandemic, the largest average increase in our sample. Countries that suffered larger infection rates seem to have experienced larger REU increases; e.g., France 97.4\%, Italy 83.94\%, and Portugal 77.4\%. Even among countries that were relatively less impacted by COVID-19, in terms of

\footnotetext{
${ }^{7}$ More details on the international equity index portfolios can be found at Kenneth French's data library available at https://mba.tuck.dartmouth.edu/pages/faculty/ken.french/Data_Library/int_index_ port_formed.html
} 
low numbers of confirmed cases and deaths, REUs still rose sharply in the first quarter of 2020; e.g., Japan 19.5\%.

[Table 3 here]

In addition to the documented comovement among REUs, especially during global crises, there are also important differences in the dynamics of REUs among countries. In particular, the patterns in Figure 1 reveal that spikes of real economic uncertainty measures are also driven by idiosyncratic events, such as during the 2012 euro-area crisis for European countries, the Brexit referendum for the United Kingdom in 2016, the Greek sovereign debt crisis that started in 2010, and the 1997 Asian financial crisis for Korea. The evidence in Table 2 also suggest that REUs are, in general, more volatile in emerging markets, such as Brazil and Turkey. For instance, while REUs in Australia and Brazil have similar historical means, the standard deviation of Brazil's REU is 4 times larger than that of Australia. Table 4 reports average correlations between REUs across all countries in our sample. We find that real economic uncertainties in many countries exhibit idiosyncratic movement and are weakly correlated with other countries REUs. For instance, we find that the U.S. REU is on average $32 \%$ correlated with the other 29 countries' REUs, with a minimum correlation of $2 \%$. Given the size of the US economy, it's not surprising that correlation of U.S. REU with other countries is higher than the average. Across all countries, the average correlation with other countries' REUs is 25\%, ranging from $14 \%$ for New Zealand to $44 \%$ for Slovenia, which provides preliminary evidence for the global nature of REU..$^{8}$ We explore the global nature of REU further in the remainder of the paper by first documenting the spillover effects of REU across countries, then exploring the economic determinants of these spillovers, and finally proposing a global measure of REU.

[Table 4 here]

\section{Domestic and international spillover effects of REU}

In this section, we first investigate the dynamic link between our REU measures and each country's (domestic) real activity. We then study the spillover effects from foreign REUs to domestic real activity.

\footnotetext{
${ }^{8}$ To put the correlations among REUs in perspective, the average correlation among economic policy uncertainty (EPU) indexes for a sample of 20 countries running from January 1997 to January 2021 is $45 \%$ (data source: www.policyuncertainty.com), while the correlation between option-implied volatility indexes for representative stock market indexes for 7 advanced economies for a sample running from January 2000 to December 2020 is $89 \%$ (data source: Bloomberg).
} 


\subsection{Domestic effects}

To assess the domestic economic effects of REU, we estimate a monthly vector-autoregressive regression (VAR) for each country wherein we establish a dynamic relation between REU and real activity, measured by industrial production (IP) 9 The VAR setting allows us to control for endogeneity between IP and REU, as it has become standard in the literature assessing the economic effects of uncertainty (see, for instance, Baker and Bloom (2013) and Ludvigson et al. (2020b)). In this regression, we control for other factors that might influence each country's IP, including the state of the economy and financial conditions. Specifically, for each country $i$, we estimate the following monthly VAR:

$$
X_{i, t}=u_{i}+\sum_{l=1}^{T} X_{i, t-l}+e_{i, t}
$$

where vector $X_{i, t}$ contains the following variables (in this order): the VIX (option-implied volatility of the S\&P 500, source: Bloomberg), the REU index, and the log of IP 10 The covariance matrix of the VAR residuals is orthogonalized using a Cholesky decomposition with the variables ordered as mentioned above. We consider 12-monthly lags $(T=12)$ 11 We follow Bloom (2009) and order uncertainty before IP so that shocks to uncertainty impact the real activity contemporaneously but not vice versa. ${ }^{12}$ The posterior distributions of all VAR parameters are estimated using Bayesian estimation with flat priors.

Figure 2 shows the median impulse response functions and $68 \%$ confidence bands for the effect of a shock in domestic REU on each country's IP. Our results suggest that, for most countries, a rise in domestic REU is followed by a significant decline in IP for horizons of up to 60 months. Hence, our evidence extends the evidence in JLN for the domestic economic effects of U.S. uncertainty, and serve as validation that our REU measures accurately reflect uncertainty on aggregate economic activities for the countries in our sample. Our results also suggest some level of heterogeneity in the domestic economic effects of REU. For instance,

\footnotetext{
${ }^{9}$ An alternative measure of real activity is the GDP. However, for all countries in our sample, GDP is only available at the quarterly frequency, whereas IP is available at the monthly frequency. Because our REU measure is constructed at the monthly frequency and the literature has found that the uncertainty shocks are typically not persistent (see, for instance, Ludvigson et al. (2020a)), we thus use IP despite GDP being a broader measure of real activity. Nevertheless, the correlation between IP growth and GDP growth for the countries in our sample is as high as $91.7 \%$. In unreported results, we show that a quarterly VAR using GDP delivers qualitatively similar domestic and spillover effects of REU for economic activity.

${ }^{10}$ We use the VIX to control for global financial conditions. In unreported results, we show that using the broad dollar index (source: Federal Reserve Board) to characterize global financial conditions yields very similar results for the domestic and spillover economic effects of REU.

${ }^{11}$ Our results remain qualitatively robust to alternative lags. Ordering the VIX last in vector $X_{i, t}$, as in JLN, also yields qualitatively robust results.

${ }^{12}$ In any case, our results are highly robust if the IP is put before REU. Results for the robustness tests are available, upon request, from the authors.
} 
while IP responses to shocks in REU are long lived (i.e., significant for horizons longer than 60 months) for several advanced economies, including the United States, the United Kingdom, Spain, Japan, Canada, and Australia, responses in other countries are only significant for horizons of less than two years (Germany, Belgium, Korea, and Turkey, among others).

Quantitatively, we find that the domestic effects of REU are economically meaningful. For instance, for the United States, we find that a four-standard deviation shock to U.S. REU, which is close to that observed after the collapse of Lehman Brothers during the 2008 GFC, leads to up to a $3 \%$ drop in U.S. IP within a year. This effect is quantitatively similar to the one reported in JLN (see Figure 6 of their paper). For other countries, a four-standard deviation shock to domestic REU, is followed by drops in domestic output within the 60-month horizon ranging between $1.6 \%$ and $8.4 \%$. In particular, we find that IP in most emerging market economies in our sample (Mexico, Turkey, Poland, and Brazil) decreases more than in advanced economies following shocks in REU.

\subsection{International spillover effects}

To assess the spillover effects of REU across countries, we extend the vector in Equation (2) to include foreign variables, as follows:

$$
X_{i, j, t}^{E x t}=u_{i, j}+\sum_{l=1}^{T} X_{i, j, t-l}^{E x t}+e_{i, j, t}
$$

where vector $X_{i, j, t}^{E x t}$ includes the following variables (in this order): the VIX, the REU index of country $i$, the REU index of country $j$, the log of IP of country $i$, and the log of IP of country $j$. Similar to the VARs in the section 2, the covariance matrix of VAR residuals is orthogonalized using a Cholesky decomposition with variables ordered as listed above. As a result, for each country $i$, the foreign REU is ordered after the domestic REU. This placement is conservative for assessing the spillover effect of the REU because, by construction, a shock to foreign REU is contemporaneously uncorrelated with the domestric REU and can only affect it with a lag. The posterior distributions of all VAR parameters are estimated using Bayesian estimation with flat priors.

Because the number of VAR estimates increases to the square of the number of countries considered, we summarize the spillover effects by calculating a simple measure of foreign REU with respect to each country, calculated as teh equally-weighted average of all other countries' REUs, as follows:

$$
R E U_{i, t}^{\neq i}=\frac{1}{N} \sum_{j \neq i} R E U_{j, t} .
$$


Figures 3 and 4 show the impulse response functions for the effects of foreign REU on each country's REU and IP, respectively, using the VAR in Equation (3), in which we replace country j's REU with the foreign aggregate of REU in Equation (4) 13 As can be seen in Figure 3, for all countries in our sample, greater uncertainty about underlying foreign economic conditions (an increase in foreign REU) leads to greater uncertainty about domestic economies (an increase in domestic REU). The effect of foreign REU on domestic REU peaks at horizons between one and two years, depending on the country. There are also important difference in terms of the magnitude of this effect across countries; with REU in countries like the United States and Japan being less affected by foreign REU, while REU in countries like Brazil, France, Israel, and Luxembourg experience the largest effects of foreign REU.

As can be seen in Figure 4, an increase in foreign REU also leads to a significant decline in all countries' IPs. For most countries in our sample, the economic effect of foreign uncertainty is of a similar or larger magnitude to that of the domestic uncertainty (see Figure 2). REU spillovers vary substantially across countries, although they are statistically significant for some of the horizons considered and are also economically meaningful. For instance, holding all other variables, including domestic REU, constant, a four-standard deviation increase in foreign REU is followed by a maximum drop in domestic IP within the 60-month horizon between 2 percent (Australia and the United Kingdom) and 8 percent (Slovenia). To the best of our knowledge, despite frequent references to the costs/drags from uncertainty abroad in policy discussions and in the news, this paper is the first to document the spillover effects of foreign real economic uncertainty on domestic real uncertainty and economic activity; therefore extending the existing evidence, which has mostly focused on a domestic setting for the United States.

\subsection{Economic Determinants of REU economic spillovers}

As documented in section 3.2 , the dynamic relation between foreign REU and domestic IP varies considerably across countries. In this section, we exploit this variation to investigate potential channels of transmission of REU across countries. In particular, we explore the economic determinants of the heterogeneity in the effect of REU generated in any foreign country $j$ on country $i$ 's IP. To do so, we calculate measures of trade and financial exposures for all country pairs. Trade exposure is measured as the ratio of total nominal imports plus exports between country $i$ and $j$ to the GDP of country $i$ (source: IMF). Financial exposure is measured as the ratio of total assets and liabilities of country $i$ owned and owed

\footnotetext{
${ }^{13}$ The results for the country to country spillovers are available, upon request, from the authors. In section 3.3 . we center the attention on these country to country spillovers by exploring the economic determinants of the heterogeneity in spillover effects across countries.
} 
by foreigners in country $j$ to the GDP of country $i$ (source: IMF) ${ }^{14}$ Trade and financial ties are standardized to facilitate the interpretation of the results.

To assess the explanatory power of trade and financial ties for REU economic spillovers across countries, we first use an unconditional regression setting. Specifically, we estimate the following regression using information for all country pairs:

$$
\overline{\operatorname{IRF}}_{i, j}=\beta_{0}+\beta_{\text {trade }} \overline{\text { Trade }}_{i, j}+\beta_{\text {financial }} \overline{\text { Financial }}_{i, j}+\gamma \mathbf{C}_{\mathbf{i}, \mathbf{j}}+\epsilon_{i, j},
$$

where $\overline{I R F}_{i, j}$ is the response of country $i$ 's IP to country $j$ 's REU averaged over horizons between 1 and 24 months, the horizons at which the spillover economic effects are statistically significant for most country pairs; $\overline{\text { Trade }}_{i, j}\left(\overline{\text { Financial }}_{i, j}\right)$ is the time-series average of our measure of trade (financial) exposure of country $i$ to uncertainty generated in country $j$ (for instance, the total imports plus exports between country $i$ and $j$ to the GDP of country $i$ characterizes the trade vulnerability of country $i$ to uncertainty generated in country $j$ ); and $\mathbf{C}_{\mathbf{i}, \mathbf{j}}$ includes the following control variables: the relative economic size, measured as the ratio of country $j$ 's to country $i$ 's GDP, and the geographical distance, measured as the distance in miles between any two countries' capitals. The estimated coefficients associated with trade and financial ties in the unconditional setting are reported in panel A of Table 5 . Our results suggest that trade ties significantly explain the heterogeneity in REU spillovers across countries. In particular, the negative estimated coefficient implies that a greater trade exposure makes a country's economy more vulnerable to foreign REU. The economic magnitude of this coefficient, -0.03, can be interpreted as follows. Let's assume there are three countries; country 1 is where REU originates; country 2 has a low trade exposure to country 1 that is two standard deviations lower than the average trade exposure among all countries; finally, country 3 has a high trade exposure that is two standard deviations larger than the average trade exposure. A one standard deviation increase in country 1's REU is followed by a drop in IP that ranges between 0.14 percent for country 2 and 0.27 for country 3. Although the effect of financial ties is also negative, it is not significant at any standard confidence level. This evidence supports the intuition that real economic uncertainty is transmitted more strongly through the trade channel, a channel intuitively related more strongly to real economic integration, rather than through financial integration.

A potential explanation for the lack of significance of financial ties could be the presence of outliers in our measure of financial exposure, especially because our sample includes offshore

\footnotetext{
${ }^{14}$ Data series are obtained from Tables 1 and 8 from https://data.imf.org/?sk= B981B4E3-4E58-467E-9B90-9DE0C3367363\&sId=1481568994271. These series correspond to holdings of portfolio investment securities and is based on surveys collected by each country under the auspice of the IMF.
} 
financial centers, such as Luxembourg. For these financial centers, then, financial exposures will be much larger than for all other countries in our sample, though this not necessarily translate into stronger transmission of REU from or to these countries. To explore the effects of outliers, we estimate the following extended version of the unconditional setting in Equation (12):

$$
\begin{aligned}
\overline{\operatorname{IRF}}_{i, j} & =\beta_{0}+\beta_{\text {trade }} \overline{\text { Trade }}_{i, j}+\beta_{D_{\text {trade }}} D_{\text {trade }}+\ldots \\
& +\beta_{\text {financial }} \overline{\text { Financial }}_{i, j}+\beta_{D_{\text {financial }}} D_{\text {financial }}+\gamma \mathbf{C}_{\mathbf{i}, \mathbf{j}}+\epsilon_{i, j},
\end{aligned}
$$

where $D_{\text {trade }}\left(D_{\text {financial }}\right)$ takes the value of 1 when $\overline{\text { Trade }}_{i, j}\left(\overline{\text { Financial }}_{i, j}\right)$ is above or below the $1^{\text {st }}$ percentile threshold; that is, when the trade (financial) exposure for a particular country pair is exceptionally low (lower than the $1^{\text {st }}$ percentile of the distribution) or exceptionally high (higher than the 99th percentile of the distribution) with respect to the exposures among all country pairs in our sample. The estimated coefficients associated with trade and financial ties after controlling for outliers ( $\beta_{\text {trade }}$ and $\beta_{\text {financial }}$, respectively) are reported in panel $\mathrm{B}$ of Table 5. Indeed, the results for financial ties are much more sensitive to outliers than the results for trade ties. In particular, controlling for 1 percent outliers makes the coefficient associated with financial ties (for countries with "less extreme" financial ties; i.e., $D_{\text {financial }}=0$ ) significant ${ }^{15}$ The results for the significant explanatory power of trade ties hold when we control for outliers 16

The results in Table 5 rely on impulse responses calculated using the full sample and averaged over multiple horizons. Moreover, by using time-series averages of trade and financial ties, we ignore the potential effects of the time variation in these exposures. To explore the determinants of heterogeneous REU spillover effects in a dynamic setting, we estimate a panel-data version of the VAR in Equation (3), wherein we center the attention on the equation where the log of IP is the left-hand-side variable:

$$
i p_{i, t+h}=u_{i, j}+\beta_{f, i, j, t} R E U_{j, t}+\beta_{d, i, j} R E U_{i, t}+\beta_{i p_{i}, i, j} i p_{i}+\beta_{i p_{j}, i, j} i p_{j}+\epsilon_{i, j, t},
$$

where $i p$ is the log of industrial production and

$$
\beta_{f, i, j, t}=\gamma_{1}+\gamma_{\text {trade }} \text { Trade }_{i, j, t-1}+\gamma_{\text {financial }} \text { Financial }_{i, j, t-1}+\eta \mathbf{C}_{\mathbf{i}, \mathbf{j}, \mathbf{t}-\mathbf{1}} \text {. }
$$

\footnotetext{
${ }^{15}$ In unreported results, we show that controlling for 2 and 5 percent outliers turns the coefficient associated with financial ties positive, although not significant. This positive estimated coefficient may be counterintuitive, as it implies that larger financial ties imply lower REU spillover effects.

${ }^{16}$ In unreported results, we assess the robustness of the (lack of) explanatory power of financial ties to manually removing the offshore financial centers in our sample: Luxembourg and Ireland (due to lack of data, Switzerland is not considered for this exercise). We find that removing each country individually or both countries simultaneously yields that financial ties are not significant determinants of the heterogeneity in the effect of foreign REU.
} 
In the setting in Equations (8) and (9), all $\beta$ s are country-pair specific. However, the coefficient associated with foreign REU, $\beta_{f, i, j, t}$, varies across country pairs depending on trade and financial ties between the two countries ${ }^{17}$ Therefore, this setting allows us to assess the role of trade and financial ties at explaining the cross-country variations in the effects of foreign REU in a conditional setting. For simplicity, to reduce the number of coefficients being estimated, we assume only one lag in this regression, in contrast to the 12 lags assumed in Equation (3).

Table 6 shows the estimate of the $\gamma$ coefficients in Equation (9). Our results support the evidence in Table 5 that trade exposure is the main driver of the transmission of REU across countries. The coefficient associated with trade ties is negative and significant at any standard confidence level for horizons longer than 1 month. In contrast, as in Table 5 , financial ties cannot explain the heterogeneous responses of domestic IPs to foreign REUs across countries.

\section{Global REU and its economic effects}

So far, we have documented that both REU originated domestically and that originated in foreign countries have a statistically significant effect on domestic IP. We also establish that the main channel through which uncertainty abroad affects domestic IP is trade; greater trade ties imply a larger effect of foreign REU on domestic IP. Building on these two results, in this section, we propose a novel measure of global REU, analyze its dynamics, and assess its dynamic relation with all countries' economic activity indicators.

\subsection{A novel measure of global REU}

Based on the evidence in section 3.3 that trade ties are the main determinant of the economic spillovers of foreign REU, we propose a novel index of global REU, which is calculated as the trade-weighted average of all countries' REUs,

$$
R E U_{t}^{\text {Global }}=\frac{\sum_{j=1}^{N} \text { Trade }_{j} \times R E U_{j, t}}{\sum_{j=1}^{N} \text { Trade }_{j}},
$$

where $N=30$ is the total number of countries in our sample and Tradej is country $j$ 's total trading volume, which is measured as the total exports plus imports of goods and services from country $j$ to the rest of the world. Figure 5 plots the time series of the global REU index. Given the dynamics of country-specific REUs documented in section 2.2, it is not

\footnotetext{
${ }^{17}$ Trade and financial ties are only available at the annual frequency and, for the purpose of this exercise, are assumed constant for all months in the previous year.
} 
surprising that global uncertainty increases around global recessions, such as the 2008 Global Financial Crisis (GFC) and, more recently, the COVID-19 crisis in 2020, where it reaches its maximum value.

\subsection{Spillover effects of global REU}

To assess the economic effects of global REU, we repeat the exercise in section 3.2 and estimate a VAR for the dynamic relation between each country's IP and global REU. To disentangle the domestic and spillover economic effects of REU, for each country $i$, we first calculate the foreign component of the global REU index as the trade-weighted average of REUs among all other countries:

$$
R E U_{i, t}^{\text {Foreign }}=\frac{\sum_{j \neq i} \text { Trade }_{j} \times R E U_{j, t}}{\sum_{j \neq i} \text { Trade }_{j}} .
$$

The variables in the VAR are then the domestic REU, the foreign component of global REU, and the domestic IP.

The impulse-response functions for the effect of the foreign component of global REU on domestic IPs are shown in Figure 6. To facilitate the comparison, we also show the estimated responses for the VAR with the equal-weighted foreign REU measure (also shown in figure 4). Although the response patterns of IP to shocks in foreign REU are similar to those in figure 4, the trade-weighted measure of foreign REU yields larger negative effects on domestic IP than the equally-weighted foreign REU for 19 out of 30 countries in our sample, which is consistent with our findings that trade ties play a key role at explaining the negative effects of foreign uncertainty on domestic economic outcomes. Thus our novel global and foreign REU measures seem to reflect better uncertainty on aggregate economic activities for all countries in our sample.

We now compare the economic effects of domestic and foreign REUs for each country. Table 7 reports the VAR model's forecast error variance decomposition of the response of domestic IP due to shocks to domestic REU and to shocks to the foreign component of global REU. For all countries, we report the average as well as the maximum contribution of each shock within the 60-month horizon. Our evidence suggests that, while domestic and global REUs are both important contributors, on average, innovations to foreign REU yield a larger contribution to the variations in domestic IP than domestic REU shocksacross all 30 countries in our sample, on average, the domestic REU can contribute up to $19 \%$ of the variation in domestic IP, whereas the foreign REU can contribute up to $28 \%$ of its variation. This finding highlights the economic relevance of the transmission of foreign economic uncertainty across the globe. 
There are, however, some differences in the relative effect of domestic and foreign REUs. For instance, for Israel, the average contribution of a shock in the foreign component of global REU is as high as $58 \%$ over the 60 -month horizon, while domestic REU shocks only contribute to $10 \%$ of the variation in domestic IP. There are also some exceptions to the dominant effect of the foreign component of global REU. For the United States, for instance, although foreign REU has significant economic effects, domestic REU contributes more than foreign REU, and the dominance of domestic REU shocks holds for either the average or the maximum contribution. The finding for the United States might provide support to the evidence for the role of trade ties in explaining the heterogeneity in the foreign effects of REU documented in Table 5, as U.S trade exposure to other countries tends to be smaller than the trade exposure of other countries to the United States, which might make domestic factors more determinative of real economic activity.

[Table 7 here]

\subsection{Sectoral spillovers of global REU}

To further explore the channel through which foreign REU transmits across countries, we now dissect IP into its tradeable and nontradeable components, which are proxied by manufacturing and retail sales, respectively. The manufacturing and retail services components of IP have the advantage of being available for all countries in our sample, which guarantees the consistency and cross-country comparability of our results.

We repeat the same VAR in section 3.2 but replace the industrial production by either the production from the manufacturing sector or from the retail sales sector. Figure 7 reports the impulse-response functions for the effect of the foreign component of global REU on domestic manufacturing production (in blue) and retail sales (in red) for all countries in our sample, along with the 68-percent confidence intervals for each case. For almost all countries, a positive shock to the foreign component of global REU leads to a persistent and sizable decline in the manufacturing sector component; on average, a one-standard deviation increase in the foreign component of global REU is followed by a $0.5 \%$ decrease in manufacturing production. The maximum negative impacts of foreign REU on the manufacturing sector are statistically significant in all 30 countries. In stark contrast, the spillovers of global REU to the nontradable retail sales sector is, in general, more modest - in 28 out of the 30 countries, the maximum effect of a rise in foreign REU in the service industry sector is smaller than that in the manufacturing sector. In addition, the maximum negative impact of foreign REU on the service component of IP is statistically significant in only 13 out of the 30 countries. On average, across all countries, a one-standard deviation increase in the foreign component 
of global REU gives rise to a mere $0.02 \%$ decrease in retail sales, which is more than 10 time smaller than that for the tradable manufacturing sector, and this effect is not statistically significant at any standard confidence level 18

There are a few notable exceptions of countries for which the effect of foreign REU on the manufacturing sector is of a similar or even smaller magnitude than that on the retail sales sector. Interestingly, for most of these countries, the travel industry, the component of the retail sales sector potentially more exposed to foreign developments, represents a much larger fraction of total services with respect to all countries in our sample - the average fraction of travel to total services is $27.3 \%$ for all countries in our sample, compared to $52.1 \%$ for Spain, $51.1 \%$ for Portugal, $47.6 \%$ for Iceland, and $43.3 \%$ for Greece (source: WTO using 2019 data).

In sum, we find consistent evidence that, in response to a rise in foreign real economic uncertainty, the decline in domestic industrial production is mainly attributable to the sharp decrease in production from the tradable manufacturing sector. These findings reinforce our evidence that trade exposure is the key driver of the transmission of global economic uncertainty across countries.

\section{Conclusion}

Even as economic and financial connections across countries have risen and uncertainty abroad is increasingly cited as a headwind to domestic economic performance, the transmission of real economic uncertainty across countries remains largely unexplored. We focus on an econometric-based measure of real economic uncertainty which can be interpreted as the (lack of) predictability of future economic outcomes based on current and past economic and financial information. Following the methodology of Jurado, Ludvigson, and Ng (2015), we calculate real economic uncertainty (REU) indexes for 30 advanced and emerging market economies comprising 65 percent of global GDP. We show, first, that measures of REU for the economies in our sample have statistically significant and economically meaningful effects on domestic output, extending previous work using REU measures, which has focused primarily on the United States. We next establish that REU abroad also weighs on domestic economies in statistically and economically meaningful ways. To provide insight into the channels through which uncertainty abroad affects domestic economies, we examine traditional trade and financial channels. We find that the stronger the trade ties are across countries, the stronger the spillover effects are of economic uncertainty. Moreover,

\footnotetext{
${ }^{18}$ In unreported results, which are available upon request, we show that the average decline in the retail sales sector component is not statistically significant according to the 68 percent confidence intervals, whereas the average decline in manufacturing production is statistically significant.
} 
foreign real economic uncertainty, measured as a trade-weighted average of all other countries' REUs, has a greater impact on the tradeable domestic sector than the nontradeable sector of a country's industrial production, providing further evidence of the trade channel of transmission. Thus, we not only extend the existing evidence for the United States to a large sample of countries but document the international transmission of real economic uncertainty and provide a fundamental explanation for this transmission. Based on this evidence, we propose a global measure of real economic uncertainty as a trade-weighted average of all countries' REUs. Our work supports the intuition that, like financial uncertainty, real economic uncertainty has a global nature but its transmission across countries in fundamentally linked to trade ties, instead of to financial ties.

\section{References}

Alfaro, I., Bloom, N., Lin, X., 2016. The real and financial impact of uncertainty shocks. In: Stanford Institute for Theoretical Economics (SITE) 2016 Workshop. Retrieved from https://site. stanford. edu/sites/default/files/alfaro. pdf.

Altig, D., Barrero, J. M., Bloom, N., Davis, S. J., Meyer, B. H., Parker, N., 2020. Surveying business uncertainty. Journal of Econometrics (forthcoming) .

Angelini, G., Bacchiocchi, E., Caggiano, G., Fanelli, L., 2019. Uncertainty across volatility regimes. Journal of Applied Econometrics 34, 437-455.

Bai, J., Ng, S., 2002. Measuring economic policy uncertainty. Econometrica 70, 191-221.

Baker, S. R., Bloom, N., 2013. Does uncertainty reduce growth? using disasters as natural experiments. Tech. rep., National Bureau of Economic Research.

Baker, S. R., Bloom, N., Davis, S. J., 2016. Measuring economic policy uncertainty. The quarterly journal of economics 131, 1593-1636.

Balcilar, M., Ozdemir, Z. A., Ozdemir, H., Wohar, M. E., 2020. Transmission of US and EU economic policy uncertainty shock to Asian economies in bad and good times. Available at SSRN 3602333 .

Barrero, J. M., Bloom, N., 2020. Economic uncertainty and the recovery. In: Jackson Hole Economic Symposium, Federal Reserve Bank of Kansas City.

Bhattarai, S., Chatterjee, A., Park, W. Y., 2019. Global spillover effects of us uncertainty. Journal of Monetary Economics . 
Bloom, N., 2009. The impact of uncertainty shocks. econometrica 77, 623-685.

Bowman, D., Londono, J. M., Sapriza, H., 2015. U.s. unconventional monetary policy and transmission to emerging market economies. Journal of International Money and Finance pp. 27-59.

Caldara, D., Fuentes-Albero, C., Gilchrist, S., Zakrajšek, E., 2016. The macroeconomic impact of financial and uncertainty shocks. European Economic Review 88, 185-207.

Carriero, A., Clark, T. E., Marcellino, M., 2018. Measuring uncertainty and its impact on the economy. Review of Economics and Statistics 100, 799-815.

Cascaldi-Garcia, D., Sarisoy, Cisil Londono, J. M., Rogers, J., Sun, B., Datta, D., Ferreira, T., Grishchenko, O., Jahan-Parvar, M. R., Loria, F., Ma, S., Rodriguez, M., Zer, I., 2020. What is certain about uncertainty? International Finance Discussion Paper p. 73.

Cesa-Bianchi, A., Pesaran, M. H., Rebucci, A., 2020. Uncertainty and economic activity: A multicountry perspective. The Review of Financial Studies 33, 3393-3445.

Cross, J. L., Hou, C., Poon, A., 2018. International transmission of macroeconomic uncertainty in small open economies: An empirical approach .

Davis, S. J., 2016. An index of global economic policy uncertainty. Tech. rep., National Bureau of Economic Research.

Jurado, K., Ludvigson, S. C., Ng, S., 2015. Measuring uncertainty. American Economic Review 105, 1177-1216.

Kose, M. A., Prasad, E., Rogoff, K., Wei, S.-J., 2009. Financial globalization: a reappraisal. IMF Staff papers $56,8-62$.

Leduc, S., Liu, Z., 2016. Uncertainty shocks are aggregate demand shocks. Journal of Monetary Economics 82, 20-35.

Londono, J. M., Ma, S., Wilson, B. A., 2019. Quantifying the impact of foreign economic uncertainty on the us economy. FED Notes p. 08.

Londono, J. M., Xu, N., 2020. The global determinants of international equity risk premiums. Tech. rep.

Ludvigson, S., Ma, S., Ng, S., 2020a. Uncertainty and business cycles: Exogenous impulse or endogenous response? American Economic Journal: Macroeconomics . 
Ludvigson, S. C., Ma, S., Ng, S., 2020b. Covid19 and the macroeconomic effects of costly disasters. Tech. rep., National Bureau of Economic Research.

Miranda-Agrippino, S., Rey, H., 2018. World asset markets and the global financial cycle. Tech. rep., National Bureau of Economic Research.

Ozturk, E. O., Sheng, X. S., 2018. Measuring global and country-specific uncertainty. Journal of international money and finance 88, 276-295.

Shin, M., Zhong, M., 2018. A new approach to identifying the real effects of uncertainty shocks. Journal of Business \& Economic Statistics pp. 1-13.

$\mathrm{Xu}, \mathrm{N} .$, 2019. Global risk aversion and international return comovements . 
Table 1:

Sample Size and Number of Underlying Economics Series

\begin{tabular}{llllcl}
\hline Country & No. of Series & REU Sample & Country & No. of Series & REU Sample \\
\hline Australia & 63 & $1960: 07$ to 2020:04 & Korea & 105 & 1960:07 to 2020:04 \\
Austria & 64 & $1960: 07$ to 2020:04 & Luxembourg & 41 & 1960:07 to 2020:04 \\
Belgium & 61 & $1960: 07$ to 2020:04 & Mexico & 38 & 1961:07 to 2020:04 \\
Brazil & 60 & $1964: 07$ to 2020:04 & Netherlands & 61 & 1960:07 to 2020:04 \\
Canada & 74 & $1960: 07$ to 2020:04 & New Zealand & 40 & 1960:07 to 2020:04 \\
Denmark & 65 & $1960: 07$ to 2020:04 & Norway & 35 & $1960: 07$ to 2020:04 \\
Finland & 64 & $1960: 07$ to 2020:04 & Poland & 64 & $1980: 11$ to 2020:04 \\
France & 68 & $1960: 07$ to 2020:04 & Portugal & 62 & $1960: 07$ to 2020:04 \\
Germany & 74 & $1960: 07$ to 2020:04 & Slovenia & 60 & $1980: 07$ to 2020:04 \\
Greece & 60 & $1960: 07$ to 2020:04 & Spain & 60 & $1960: 07$ to 2020:04 \\
Iceland & 47 & $1960: 07$ to 2020:04 & Sweden & 65 & $1960: 07$ to 2020:04 \\
Ireland & 56 & $1960: 07$ to 2020:04 & Switzerland & 40 & $1960: 07$ to 2020:04 \\
Israel & 62 & $1975: 07$ to 2020:04 & Turkey & 66 & $1960: 07$ to 2020:04 \\
Italy & 68 & $1960: 07$ to 2020:04 & UK & 67 & $1960: 07$ to 2020:04 \\
Japan & 90 & $1960: 07$ to 2020:04 & US & 105 & $1960: 07$ to 2020:04 \\
\hline
\end{tabular}

This table shows the number of economic series used to calculate REU indexes for all countries in our sample. We also report the availability of REU series based on the availability of these economic series. All economic series are obtained from the OECD main economic indicators (MEI). 
Table 2:

\section{REU Summary Statistics}

\begin{tabular}{lllllll}
\hline Country & Mean & SD & Min & Min date & Max & Max date \\
\hline Australia & 0.72 & 0.06 & 0.62 & $1962: 08$ & 1.27 & $2020: 04$ \\
Austria & 0.76 & 0.12 & 0.54 & $1981: 09$ & 1.32 & $2020: 04$ \\
Belgium & 0.79 & 0.08 & 0.62 & $1983: 07$ & 1.39 & $2020: 04$ \\
Brazil & 0.74 & 0.23 & 0.29 & $1968: 07$ & 1.85 & $2020: 03$ \\
Canada & 0.74 & 0.12 & 0.58 & $2004: 04$ & 1.50 & $2020: 03$ \\
Denmark & 0.66 & 0.10 & 0.41 & $1984: 08$ & 0.97 & $2020: 04$ \\
Finland & 0.72 & 0.09 & 0.50 & $1987: 09$ & 1.24 & $1971: 05$ \\
France & 0.77 & 0.12 & 0.61 & $1989: 04$ & 1.90 & $2020: 04$ \\
Germany & 0.73 & 0.08 & 0.59 & $2015: 04$ & 1.34 & $2020: 04$ \\
Greece & 0.77 & 0.11 & 0.51 & $1967: 04$ & 1.17 & $2020: 04$ \\
Iceland & 0.57 & 0.12 & 0.39 & $2003: 09$ & 1.59 & $2020: 04$ \\
Ireland & 0.72 & 0.14 & 0.49 & $1977: 03$ & 1.52 & $2020: 04$ \\
Israel & 0.66 & 0.23 & 0.15 & $1981: 12$ & 1.41 & $2020: 02$ \\
Italy & 0.77 & 0.12 & 0.56 & $1968: 03$ & 1.60 & $2020: 04$ \\
Japan & 0.81 & 0.13 & 0.66 & $1994: 03$ & 1.26 & $1963: 02$ \\
Korea & 0.77 & 0.18 & 0.46 & $1972: 05$ & 1.34 & $1988: 08$ \\
Luxembourg & 0.76 & 0.16 & 0.35 & $1960: 09$ & 1.54 & $2020: 03$ \\
Mexico & 0.60 & 0.30 & 0.07 & $1966: 02$ & 1.36 & $2020: 04$ \\
Netherlands & 0.73 & 0.15 & 0.45 & $1964: 12$ & 1.31 & $2020: 04$ \\
New Zealand & 0.48 & 0.07 & 0.31 & $1960: 07$ & 0.88 & $2020: 03$ \\
Norway & 0.56 & 0.07 & 0.41 & $1984: 08$ & 0.99 & $1970: 01$ \\
Poland & 0.69 & 0.21 & 0.31 & $1982: 12$ & 1.57 & $1990: 06$ \\
Portugal & 0.72 & 0.14 & 0.47 & $1964: 01$ & 1.52 & $2020: 04$ \\
Slovenia & 0.65 & 0.33 & 0.10 & $1985: 09$ & 1.78 & $2020: 04$ \\
Spain & 0.72 & 0.10 & 0.49 & $1972: 07$ & 1.30 & $2020: 04$ \\
Sweden & 0.74 & 0.14 & 0.51 & $1987: 06$ & 1.34 & $2020: 04$ \\
Switzerland & 0.66 & 0.12 & 0.50 & $1994: 07$ & 1.36 & $1966: 05$ \\
Turkey & 0.71 & 0.17 & 0.46 & $1983: 04$ & 1.73 & $2020: 04$ \\
UK & 0.74 & 0.10 & 0.55 & $1995: 12$ & 1.26 & $2020: 03$ \\
US & 0.75 & 0.06 & 0.67 & $1988: 10$ & 1.15 & $2020: 04$ \\
\hline & & & & & & \\
\hline & &
\end{tabular}

This table shows a set of summary statistics (mean, standard deviation, minimum, date of minimum, maximum, and date of maximum) for the REU time series for all countries in our sample (see Figure 1). 
Table 3:

REU Increase due to COVID-19

\begin{tabular}{lclclc}
\hline \multicolumn{5}{c}{ Increase in REU from $2019: 12$ to $2020: 04$} \\
\hline Country & $\uparrow$ REU(\%) & Country & $\uparrow$ REU(\%) & Country & $\uparrow$ REU(\%) \\
\hline Australia & 50.26 & Iceland & 51.19 & Norway & 40.77 \\
Austria & 47.04 & Ireland & 39.52 & Poland & 59.94 \\
Belgium & 41.82 & Israel & 15.16 & Portugal & 77.40 \\
Brazil & 56.17 & Italy & 83.94 & Slovenia & 53.77 \\
Canada & 35.65 & Japan & 19.47 & Spain & 54.45 \\
Denmark & 26.02 & Korea & 21.88 & Sweden & 52.11 \\
Finland & 30.97 & Luxembourg & 27.61 & Switzerland & 56.95 \\
France & 97.41 & Mexico & 51.37 & Turkey & 63.35 \\
Germany & 62.93 & Netherlands & 53.85 & UK & 28.71 \\
Greece & 23.33 & New Zealand & 39.04 & US & 27.76 \\
\hline Avg & 46.33 & Max (France) & 97.41 & Min (Israel) & 15.16 \\
\hline
\end{tabular}

This table shows the percentage changes in REU from 2019:12 to 2020:04 for all countries in our sample. 
Table 4:

\section{REU Correlations}

\begin{tabular}{llll}
\hline \multicolumn{3}{l}{ Correlation with other } & countries' REUs \\
\hline Country & Mean & Min & Max \\
\hline Australia & 0.22 & 0.04 & 0.45 \\
Austria & 0.33 & 0.04 & 0.74 \\
Belgium & 0.35 & 0.00 & 0.70 \\
Brazil & 0.25 & 0.02 & 0.78 \\
Canada & 0.26 & 0.01 & 0.67 \\
Denmark & 0.29 & 0.01 & 0.79 \\
Finland & 0.23 & 0.04 & 0.56 \\
France & 0.35 & 0.06 & 0.53 \\
Germany & 0.22 & 0.02 & 0.55 \\
Greece & 0.32 & 0.05 & 0.69 \\
Iceland & 0.21 & 0.05 & 0.52 \\
Ireland & 0.26 & 0.00 & 0.68 \\
Israel & 0.29 & 0.04 & 0.69 \\
Italy & 0.19 & 0.02 & 0.48 \\
Japan & 0.26 & 0.02 & 0.74 \\
Korea & 0.24 & 0.01 & 0.54 \\
Luxembourg & 0.32 & 0.01 & 0.65 \\
Mexico & 0.28 & 0.00 & 0.78 \\
Netherlands & 0.32 & 0.05 & 0.66 \\
New Zealand & 0.14 & 0.00 & 0.37 \\
Norway & 0.23 & 0.01 & 0.49 \\
Poland & 0.16 & 0.01 & 0.43 \\
Portugal & 0.30 & 0.03 & 0.73 \\
Slovenia & 0.44 & 0.02 & 0.79 \\
Spain & 0.26 & 0.01 & 0.56 \\
Sweden & 0.33 & 0.02 & 0.74 \\
Switzerland & 0.24 & 0.02 & 0.70 \\
Turkey & 0.26 & 0.02 & 0.62 \\
UK & 0.26 & 0.05 & 0.63 \\
\hline Avg & 0.32 & 0.02 & 0.56 \\
\hline
\end{tabular}

This table shows the average, minimum, and maximum correlations (in absolute value) between each country's REU and those of all other countries. 
Table 5:

\section{Determinants of International REU Transmission, Unconditional Setting}

\begin{tabular}{|c|c|c|c|}
\hline \multicolumn{4}{|c|}{ Panel A. Multivariate setting } \\
\hline & Constant & $\begin{array}{c}\text { Trade } \\
\text { ties }\end{array}$ & $\begin{array}{c}\text { Financial } \\
\text { ties }\end{array}$ \\
\hline$\beta$ & -0.20 & -0.03 & -0.01 \\
\hline t-stat & -16.62 & -1.78 & -0.34 \\
\hline
\end{tabular}

Panel B. Multivariate setting, controlling for outliers

\begin{tabular}{lccc}
\hline & Constant & $\begin{array}{c}\text { Trade } \\
\text { ties }\end{array}$ & $\begin{array}{c}\text { Financial } \\
\text { ties }\end{array}$ \\
\hline$\beta$ & -0.22 & -0.05 & -0.08 \\
t-stat & -16.79 & -2.20 & -2.50 \\
\hline
\end{tabular}

Panel A shows the estimated coefficients associated with trade and financial ties in the following regression:

$$
\overline{\operatorname{IRF}}_{i, j}=\beta_{0}+\beta_{\text {trade }} \overline{\text { Trade }}_{i, j}+\beta_{\text {financial }} \overline{\text { Financial }}_{i, j}+\gamma \mathbf{C}_{\mathbf{i}, \mathbf{j}}+\epsilon_{i, j},
$$

where $\overline{I R F}_{i, j}$ is the response of country $i$ 's IP to country $j$ 's REU averaged over horizons between 1 and 24 months; $\overline{\text { Trade }}_{i, j}\left(\overline{\text { Financial }}_{i, j}\right)$ is the time-series average of our measure of trade (financial) exposure of country $i$ to uncertainty generated in country $j$; and $\mathbf{C}_{\mathbf{i}, \mathbf{j}}$ includes the following control variables: the relative economic size, and the geographical distance. We also report t-statistics calculated using OLS standard deviations. Panel B shows an extended setting wherein we control for outliers in trade and financial exposures:

$$
\begin{aligned}
\overline{I R F}_{i, j} & =\beta_{0}+\beta_{\text {trade }} \overline{\text { Trade }}_{i, j}+\beta_{D_{\text {trade }} D_{\text {trade }}+\ldots} \\
& +\beta_{\text {financial }} \overline{\text { Financial }}_{i, j}+\beta_{D_{\text {financial }}} D_{\text {financial }}+\gamma \mathbf{C}_{\mathbf{i}, \mathbf{j}}+\epsilon_{i, j},
\end{aligned}
$$

where $D_{\text {trade }}\left(D_{\text {financial }}\right)$ takes the value of 1 when $\overline{\operatorname{Trade}}_{i, j}\left(\overline{\text { Financial }}_{i, j}\right)$ is above or below the 1 percentile threshold. Due to lack of data, the following countries are not considered for this exercise: Australia, Brazil, New Zealand, and Switzerland. 
Table 6:

Determinants of International REU Transmission, Conditional Setting

\begin{tabular}{|c|c|c|c|c|c|c|c|c|c|c|c|c|}
\hline & $h=1$ & $h=2$ & $h=3$ & $h=4$ & $h=5$ & $h=6$ & $h=7$ & $h=8$ & $h=9$ & $h=10$ & $h=11$ & $h=12$ \\
\hline Trade ties & -0.01 & -0.01 & -0.01 & -0.02 & -0.02 & -0.02 & -0.03 & -0.03 & -0.04 & -0.04 & -0.04 & -0.04 \\
\hline t-stat & -1.49 & -2.11 & -2.32 & -2.81 & -3.05 & -3.11 & -3.64 & -4.00 & -4.49 & -4.74 & -4.89 & -4.89 \\
\hline \multirow[t]{2}{*}{ Financial ties } & 0.00 & -0.01 & 0.00 & 0.00 & 0.00 & -0.01 & -0.01 & -0.01 & 0.00 & 0.00 & -0.01 & -0.01 \\
\hline & -0.83 & -1.24 & -1.03 & -0.46 & -0.71 & -1.31 & -1.33 & -1.21 & -0.26 & -0.19 & -0.69 & -1.35 \\
\hline
\end{tabular}

This table shows estimates of the coefficients $\gamma_{\text {trade }}$ and $\gamma_{\text {financial }}$ in the following panel-data setting for all country pairs:

$$
\begin{gathered}
i p_{i, t+h}=u_{i, j}+\beta_{f, i, j, t} R E U_{j, t}+\beta_{d, i, j} R E U_{i, t}+\beta_{i p_{i}, i, j} i p_{i}+\beta_{i p_{j}, i, j} i p_{j}+\epsilon_{i, j, t}, \\
\beta_{f, i, j, t}=\gamma_{1}+\gamma_{\text {trade }} \text { Trade }_{i, j, t-2}+\gamma_{\text {financial }_{\text {Financial }}, j, t-2}+\eta \mathbf{C}_{\mathbf{i}, \mathbf{j}, \mathbf{t}-\mathbf{2}} .
\end{gathered}
$$

where ip is the log of industrial production, Trade (Financial) is our measure of trade (financial) ties between any two countries (standardized to facilitate interpretation), and $C_{i, j}$ includes the following control variables: the relative economic size, measured as the ratio of country $j$ 's to country $i$ 's GDP, and the geographical distance, measured as the distance in miles between any two countries' capitals. We also report t-statistics calculated using OLS standard deviations. Due to lack of data, the following countries are not considered for this exercise: Australia, Brazil, New Zealand, and Switzerland. 
Table 7:

Variance Decomposition of Domestic IP

\begin{tabular}{|c|c|c|c|c|}
\hline \multirow[t]{2}{*}{ Country } & \multicolumn{2}{|c|}{ Average Contribution (\%) } & \multicolumn{2}{|c|}{ Maximum Contribution (\%) } \\
\hline & Domestic REU & Foreign REU & Domestic REU & Foreign REU \\
\hline Australia & 16.22 & 10.43 & 22.64 & 14.17 \\
\hline Austria & 7.26 & 23.78 & 17.46 & 35.00 \\
\hline Belgium & 2.23 & 7.17 & 2.84 & 9.33 \\
\hline Brazil & 35.33 & 4.16 & 42.24 & 5.42 \\
\hline Canada & 40.92 & 4.60 & 73.08 & 6.81 \\
\hline Denmark & 0.44 & 14.57 & 1.10 & 20.06 \\
\hline Finland & 4.04 & 32.31 & 6.24 & 48.67 \\
\hline France & 11.53 & 23.26 & 15.40 & 35.89 \\
\hline Germany & 4.32 & 26.87 & 5.21 & 37.15 \\
\hline Greece & 3.17 & 30.81 & 4.27 & 51.45 \\
\hline Iceland & 14.57 & 24.94 & 26.98 & 35.25 \\
\hline Ireland & 7.95 & 4.87 & 15.72 & 6.02 \\
\hline Israel & 10.34 & 58.03 & 16.87 & 74.33 \\
\hline Italy & 0.85 & 31.39 & 2.22 & 47.37 \\
\hline Japan & 19.73 & 12.13 & 33.63 & 16.20 \\
\hline Korea & 9.74 & 14.29 & 14.98 & 20.41 \\
\hline Luxembourg & 7.81 & 23.58 & 9.46 & 33.62 \\
\hline Mexico & 36.74 & 9.60 & 45.68 & 16.48 \\
\hline Netherlands & 1.99 & 6.75 & 2.71 & 8.36 \\
\hline New Zealand & 3.57 & 6.77 & 5.54 & 8.51 \\
\hline Norway & 2.28 & 3.46 & 4.15 & 8.46 \\
\hline Poland & 18.24 & 11.40 & 25.15 & 17.12 \\
\hline Portugal & 2.38 & 32.30 & 2.86 & 51.99 \\
\hline Slovenia & 18.71 & 47.34 & 25.05 & 59.49 \\
\hline Spain & 18.71 & 20.00 & 24.57 & 34.45 \\
\hline Sweden & 5.84 & 22.54 & 6.50 & 31.43 \\
\hline Switzerland & 4.39 & 22.33 & 5.34 & 33.09 \\
\hline Turkey & 37.53 & 16.63 & 47.10 & 28.18 \\
\hline UK & 19.82 & 21.98 & 32.89 & 30.99 \\
\hline US & 20.30 & 12.55 & 27.88 & 17.18 \\
\hline Avg. & 12.90 & 19.36 & 18.86 & 28.10 \\
\hline
\end{tabular}

This table shows the average and maximum variance decompositions of domestic IP within 60 quarters to domestic and trade-weighted foreign REU (the foreign component of global REU) shocks for all countries in our sample. The VAR setting is explained in section 3.2 . 
Figure 1: Real Economic Uncertainty, Time Series (continued next page)
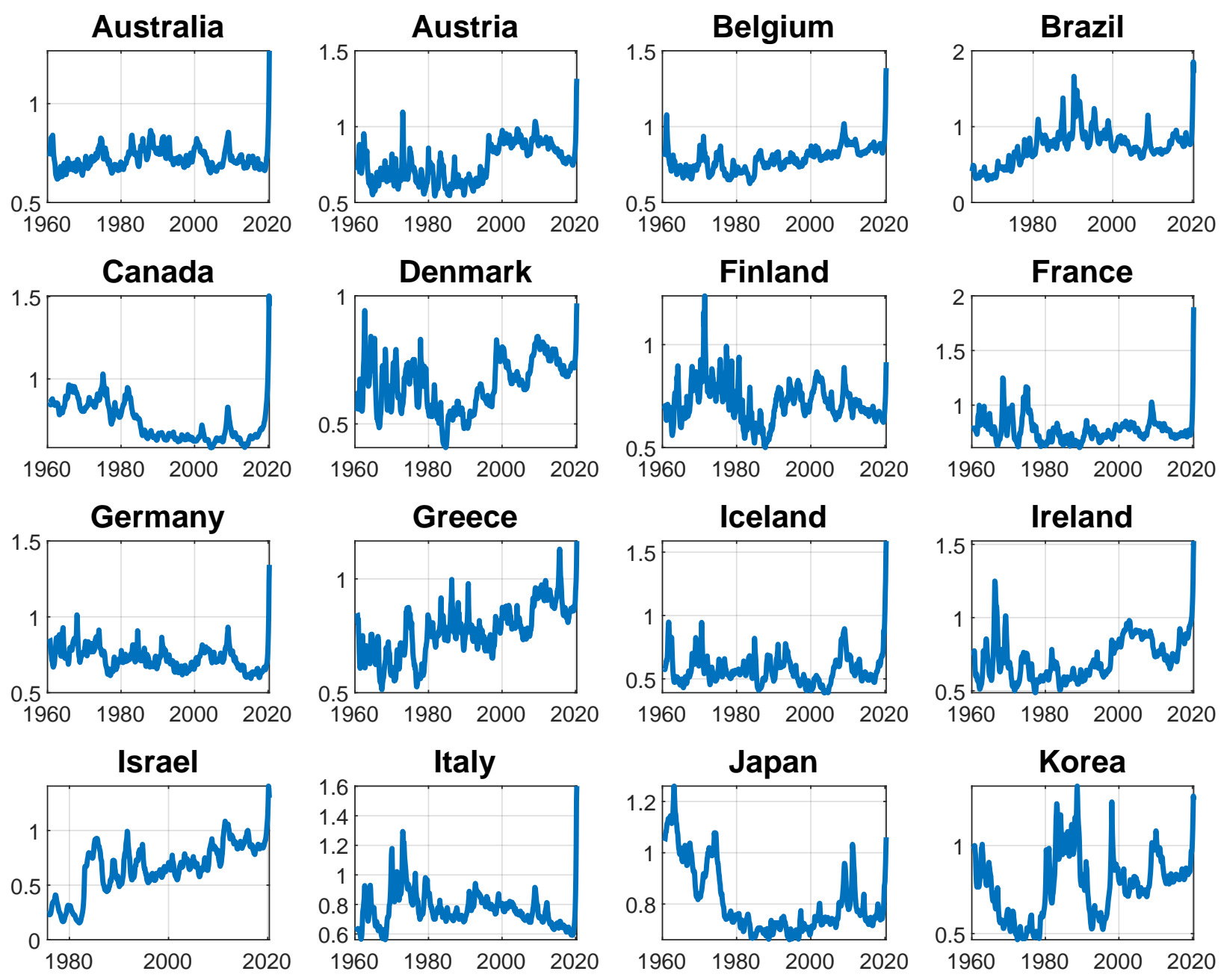

The figure shows the time series or REU indexes for all countries in our sample. Summary statistics for these time series are reported in Table 2 
Figure 1: Real Economic Uncertainty, Time Series (continued)
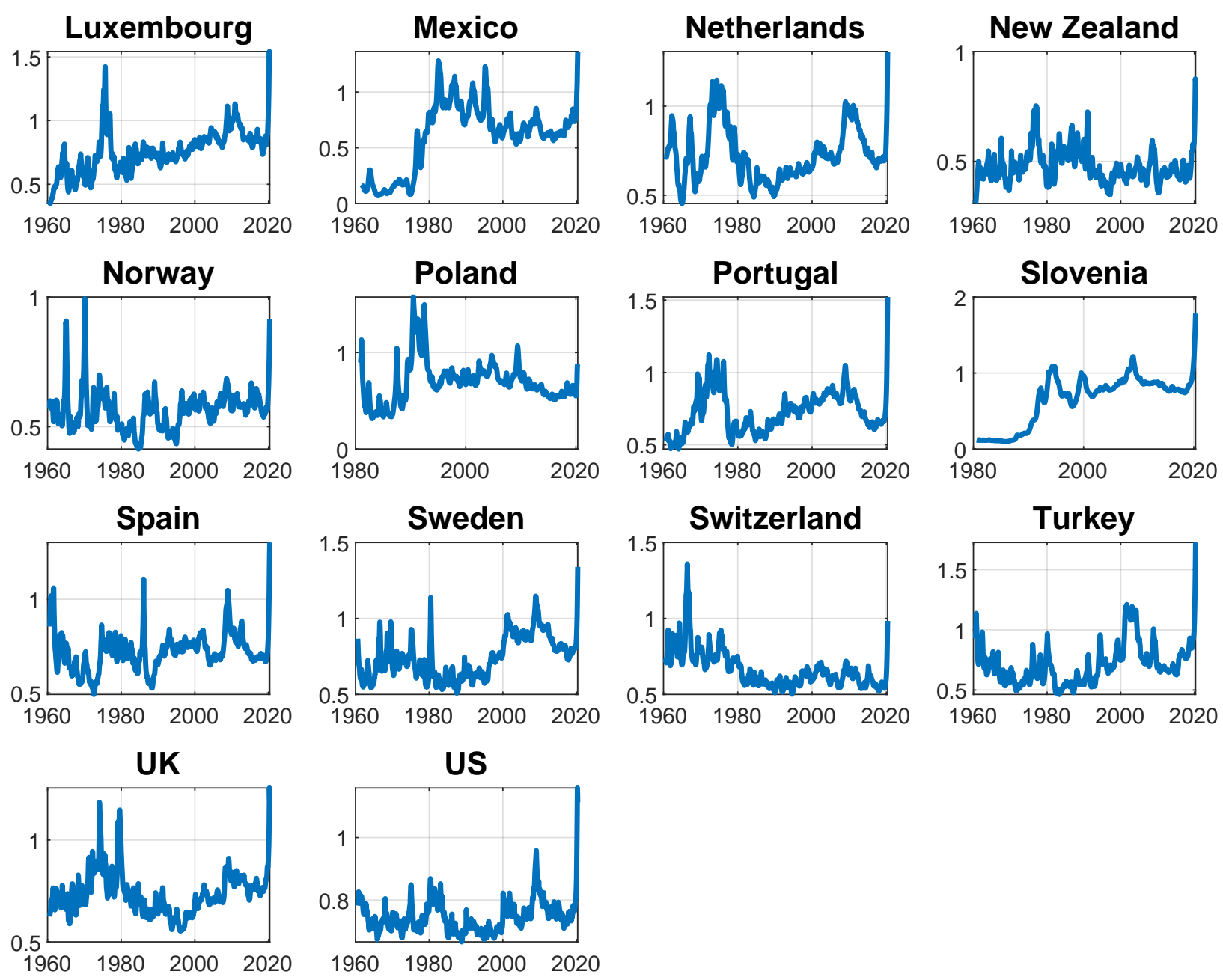
Figure 2: Domestic Effects of REU (continued next page)
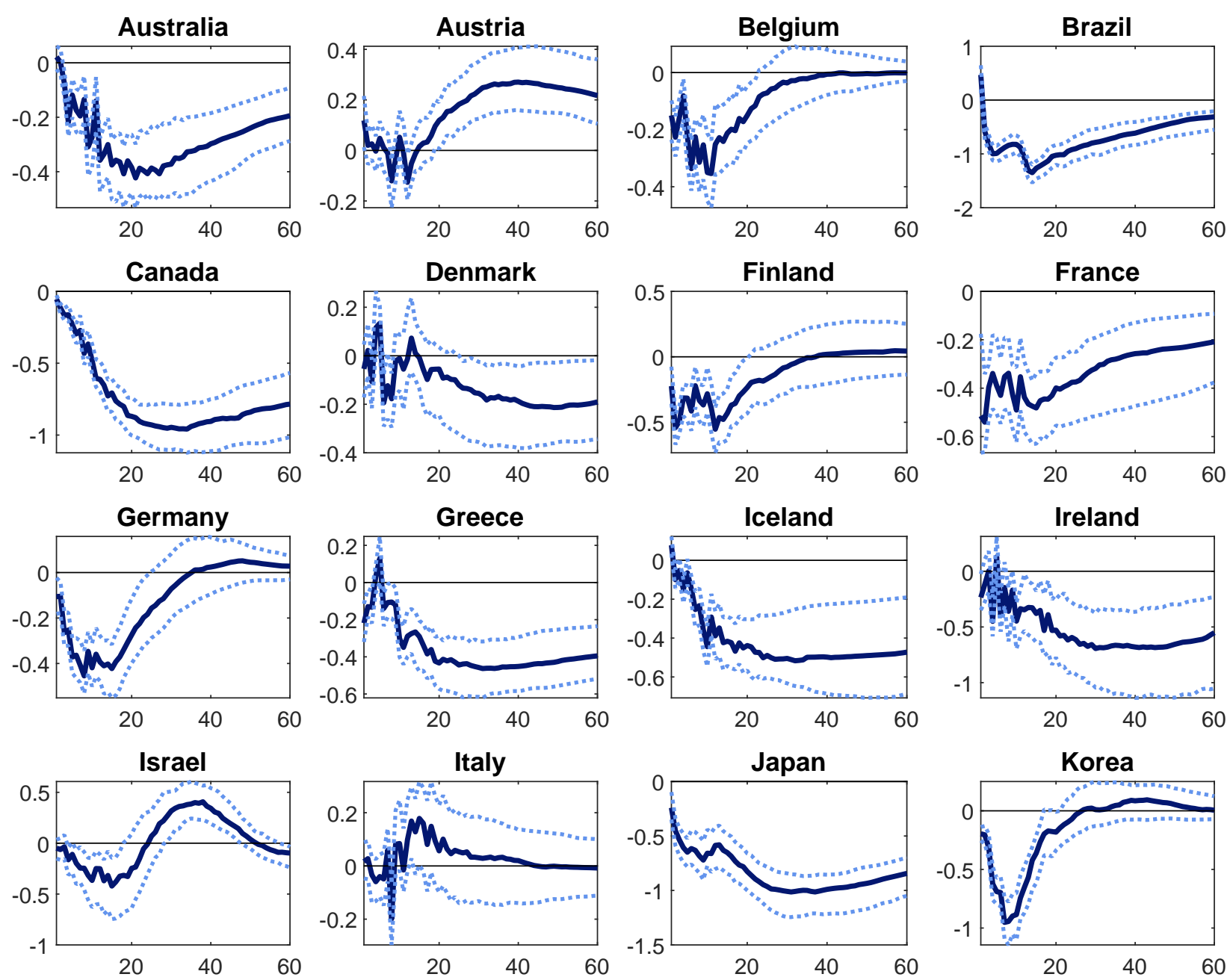

The figure shows median impulse-response functions and their 68 percent confidence intervals for the effect of (domestic) REU on (domestic) IP for all countries in our sample. The VAR setting includes the VIX, the domestic REU, and the domestic log industrial production, as explained in section 3.1 . 
Figure 2: Domestic Effects of REU (continued)
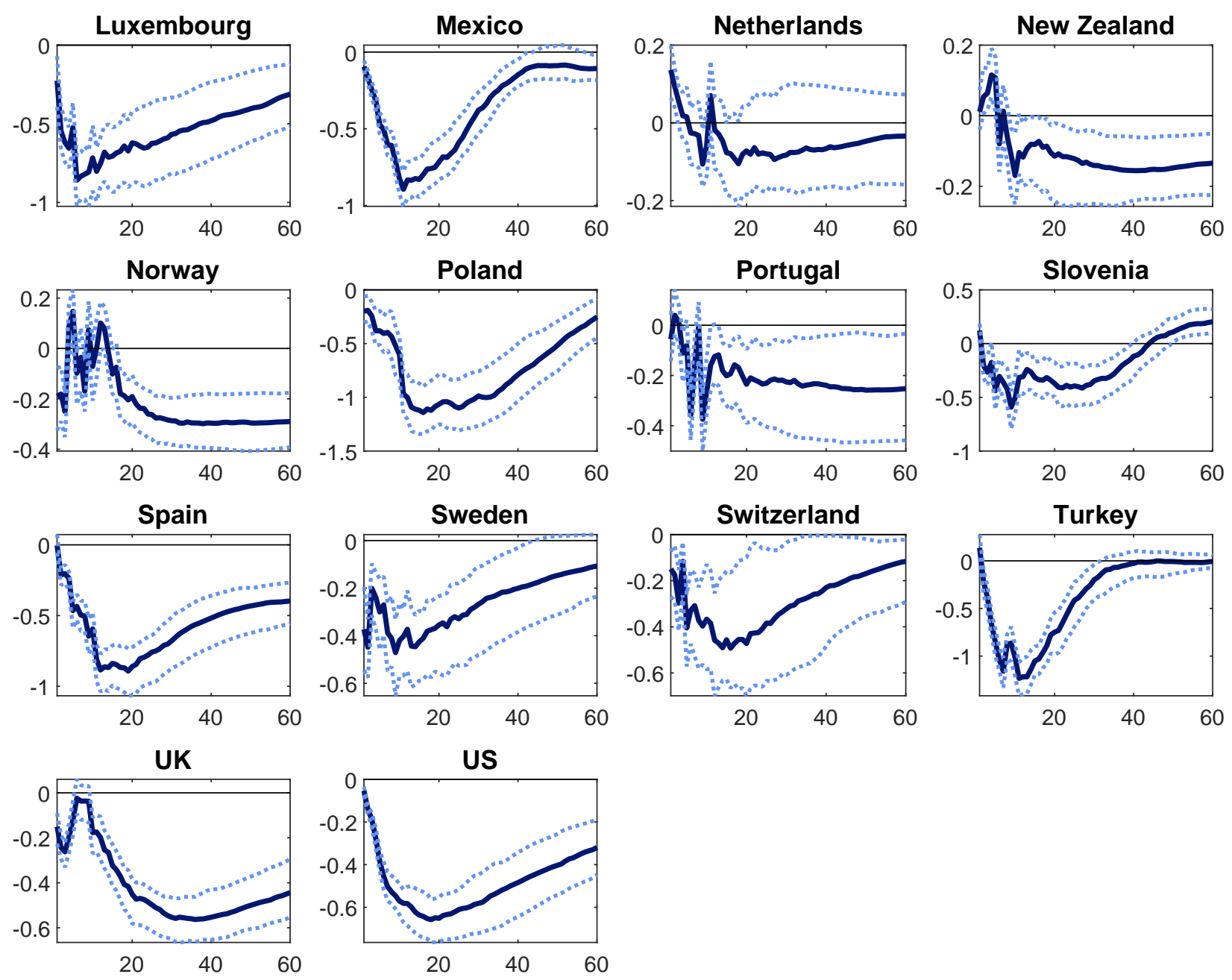
Figure 3: Spillover Effects of Foreign REU on Domestic REUs (continued next page)
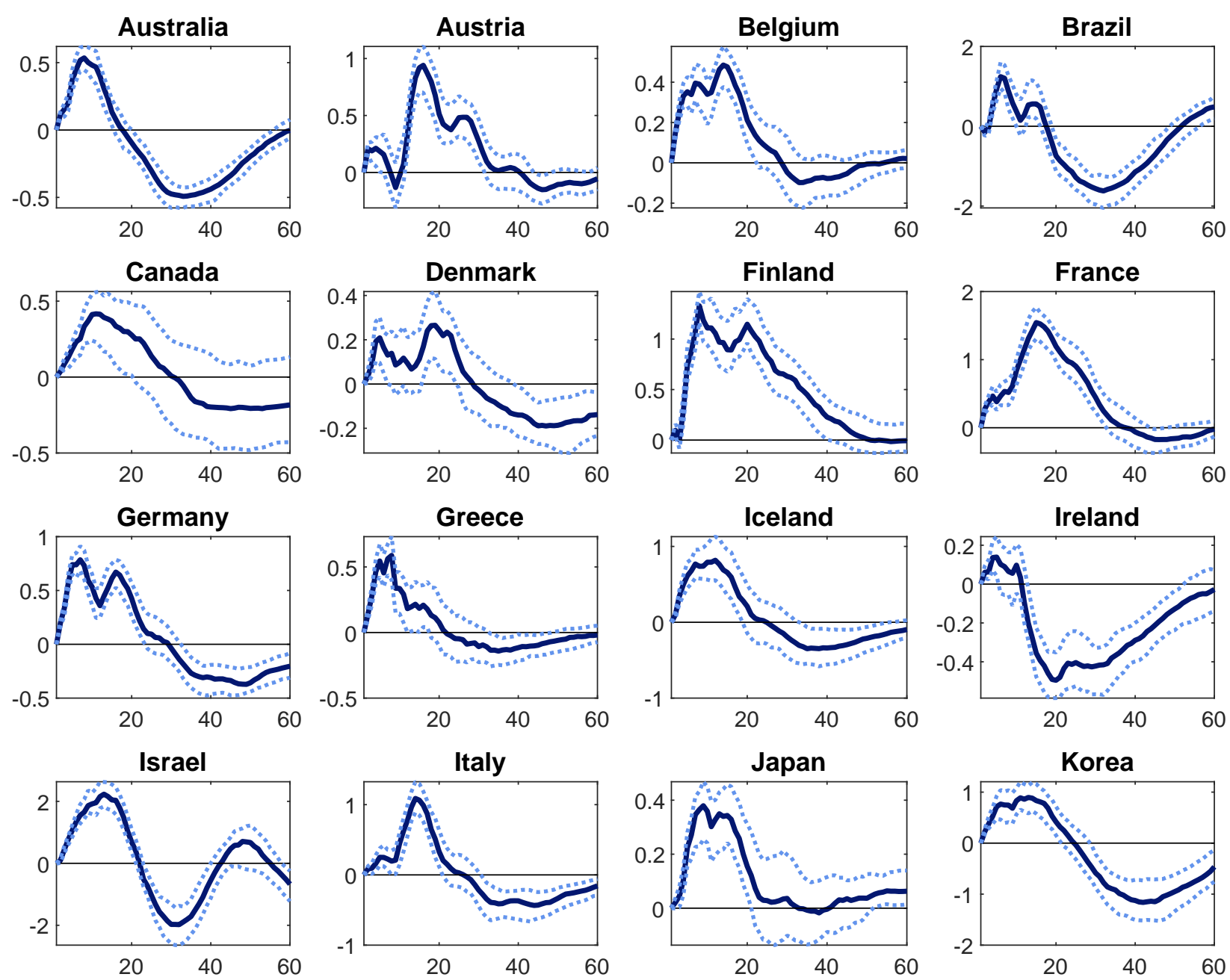

The figure shows median impulse-response functions and their 68 percent confidence intervals for the effect of a measure of foreign REU calculated as the equally-weighted average of the REU time series for all other countries (see Equation (4) ) on (domestic) REU for all countries in our sample. The VAR setting is explained in sections 3.1 and 3.2 . 
Figure 3: Spillover Effects of Foreign REU on Domestic REUs (continued)
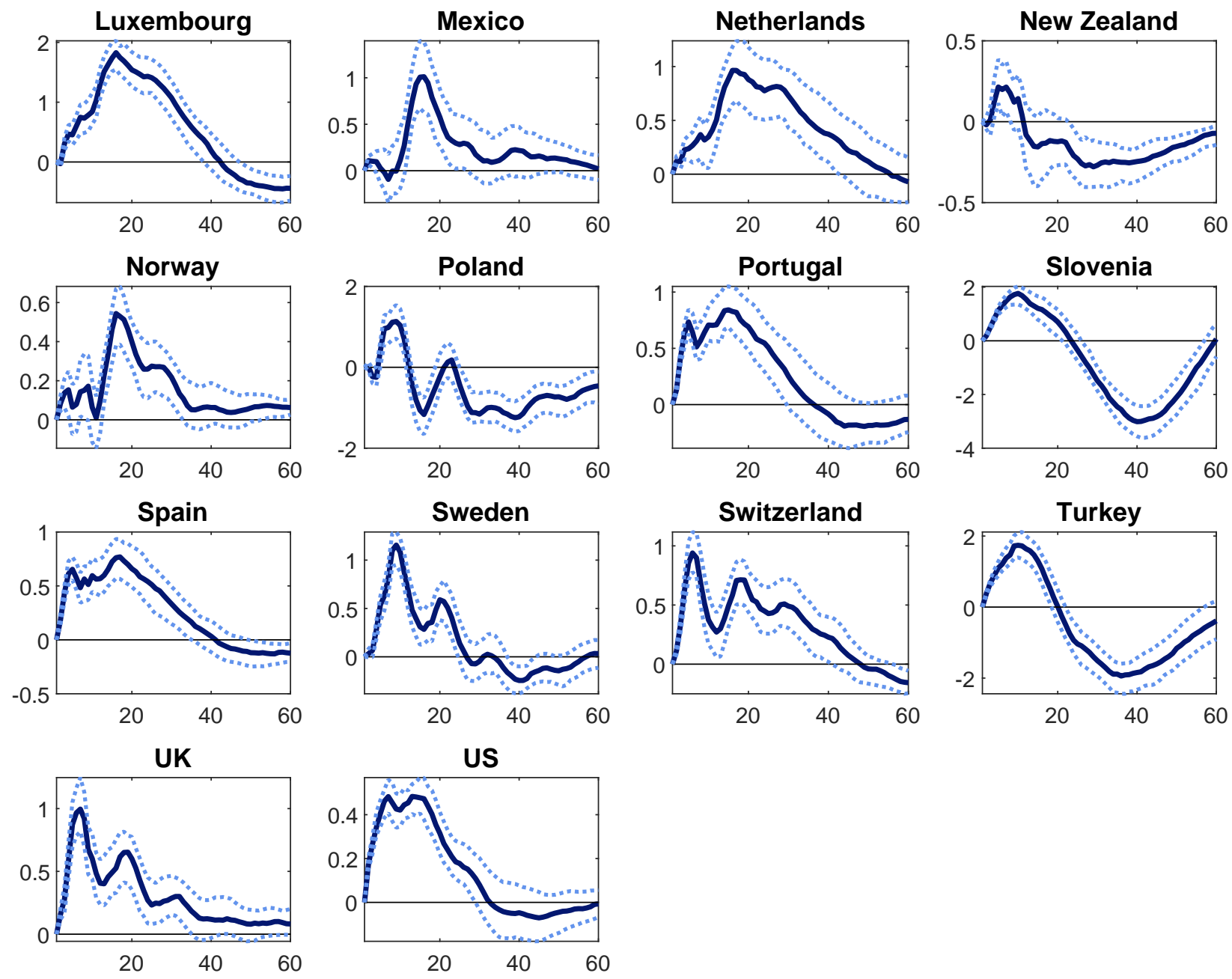
Figure 4: Spillover Effects of Foreign REU on Domestic IP Indexes (continued next page)
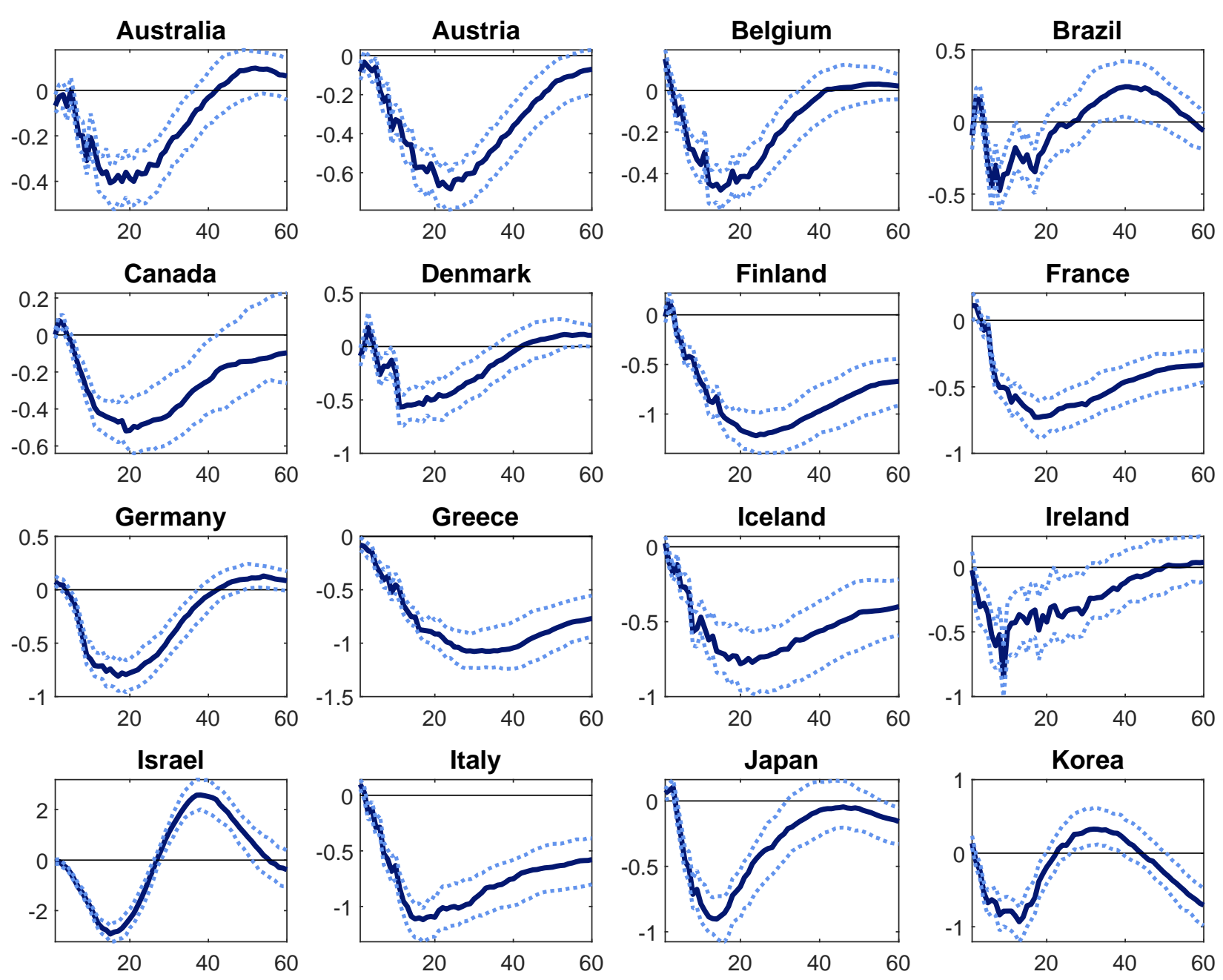

The figure shows impulse-response functions and their 68 percent confidence intervals for the effect of a measure of foreign REU calculated as the equally-weighted average of the REU time series for all other countries (see Equation (4)) on (domestic) IP for all countries in our sample. The VAR setting is explained in sections 3.1 and 3.2 . 
Figure 4: Spillover Effects of Foreign REU on Domestic IP Indexes (continued)
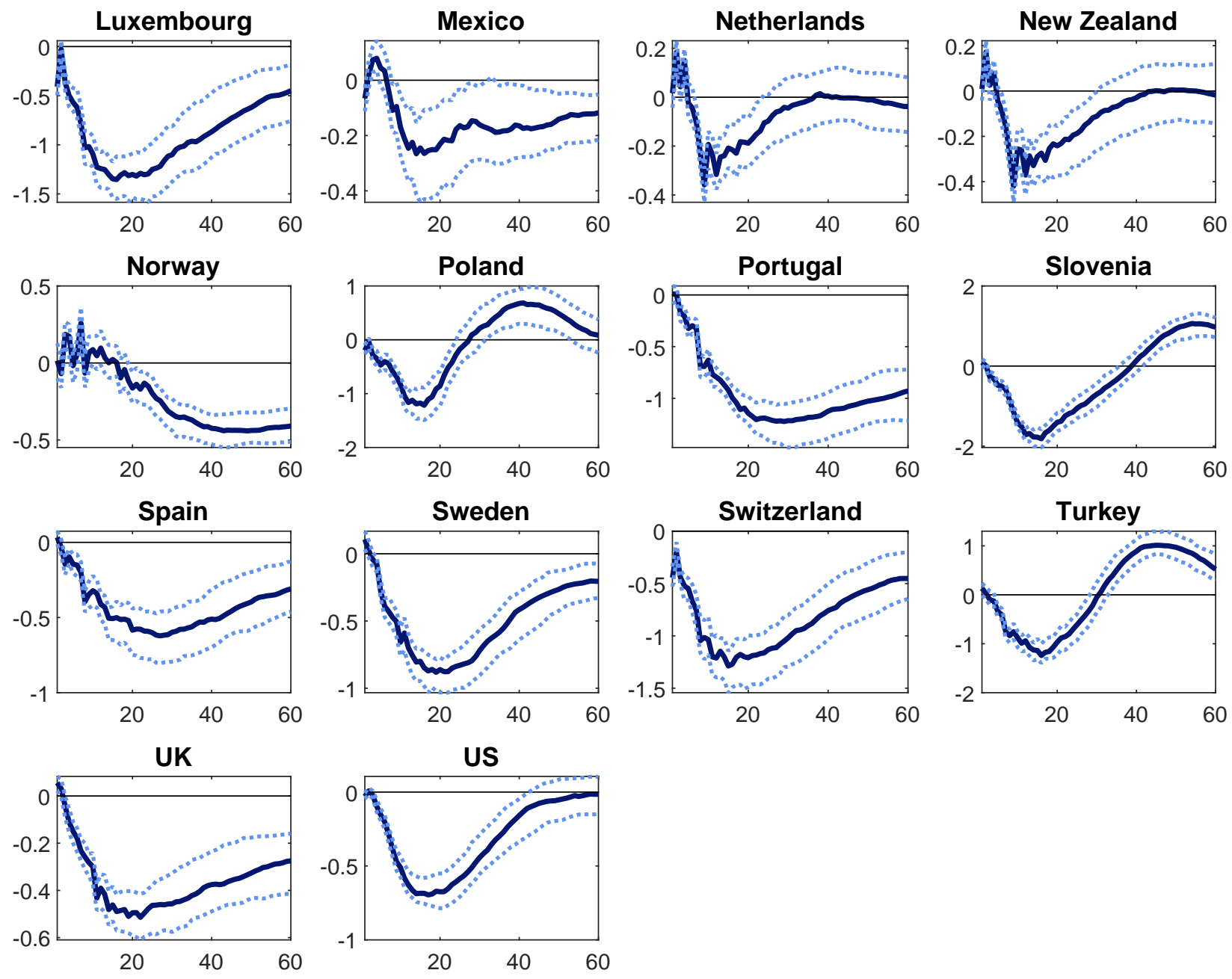
Figure 5: Global REU, Time Series

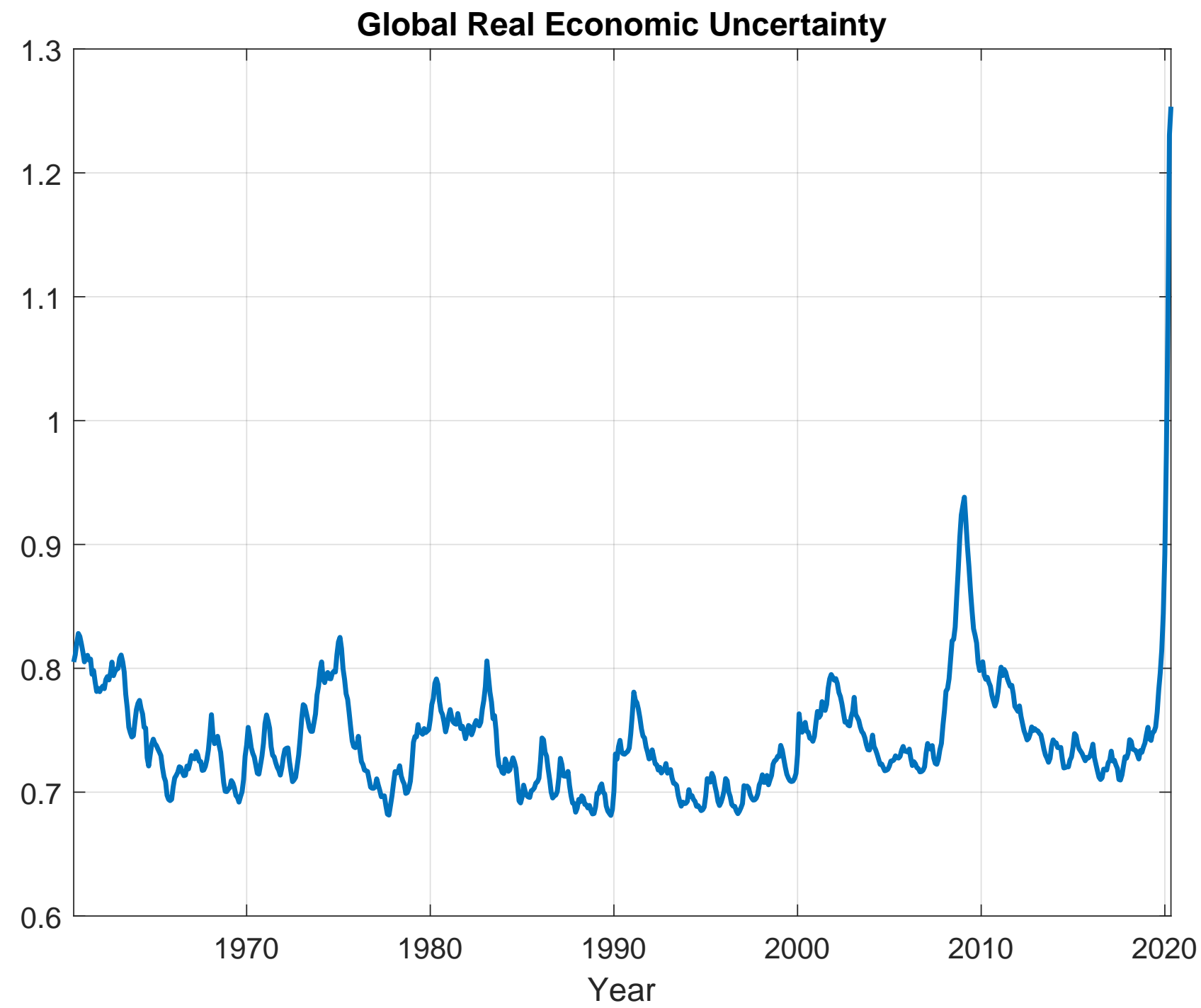

The figure shows the time series of our novel measure of one-month-ahead global REU, which is calculated as the trade-weighted average of REU across all countries in our sample (see Equation (5)). 
Figure 6: The Economic Effects of Global REU (continued next page)
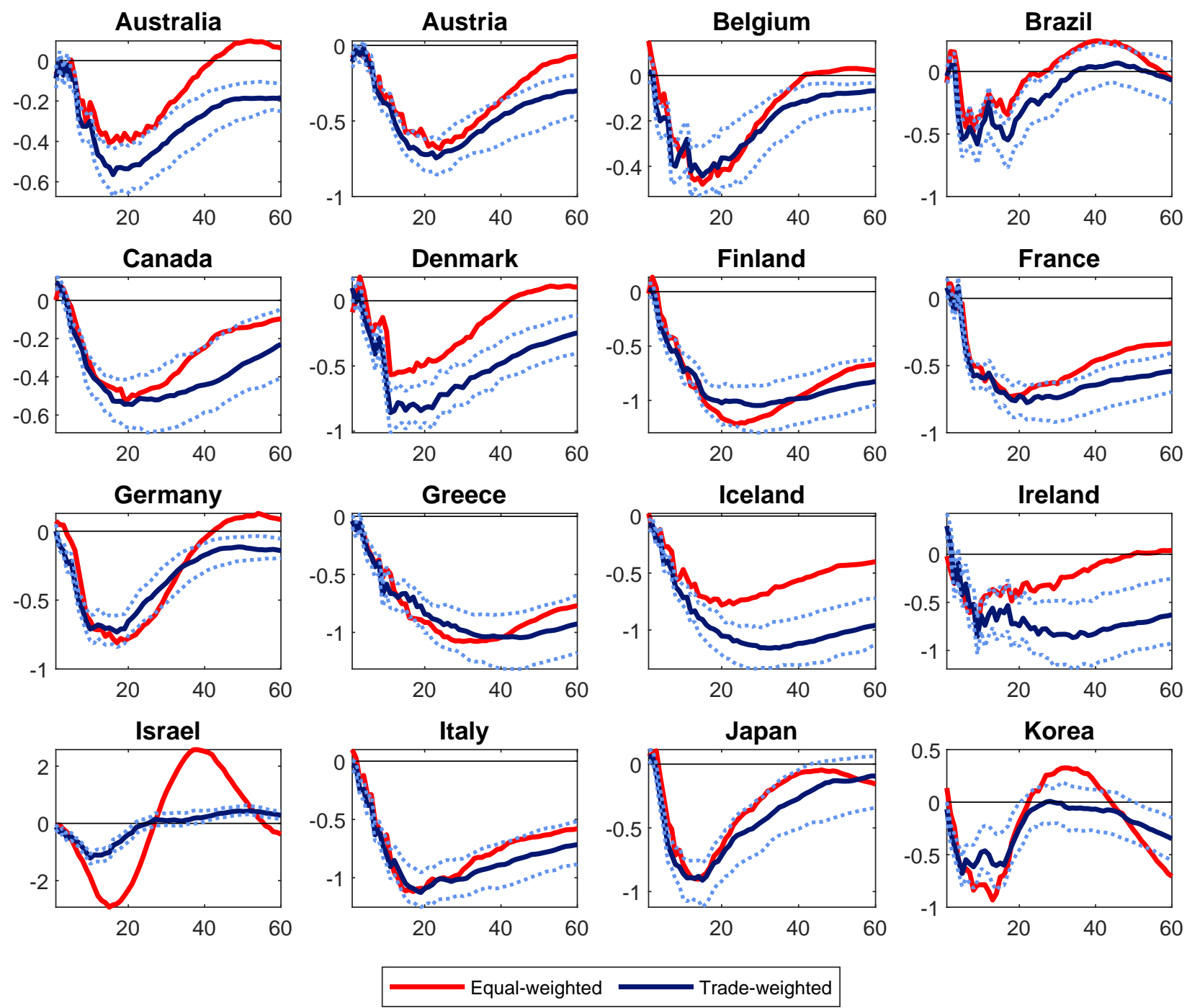

The figure shows median impulse-response functions and their 68 percent confidence intervals for the effect of a our measure of foreign REU, which is calculated as the trade-weighted average of the REU time series for all other countries (see Equation (11) ) on (domestic) IP for all countries in our sample. The VAR setting is explained in section 3.2 For comparison, we also show the impulse-response functions when the equally-weighted REU measure is considered (see figure 4). 
Figure 6: The Economic Effects of Global REU (continued)
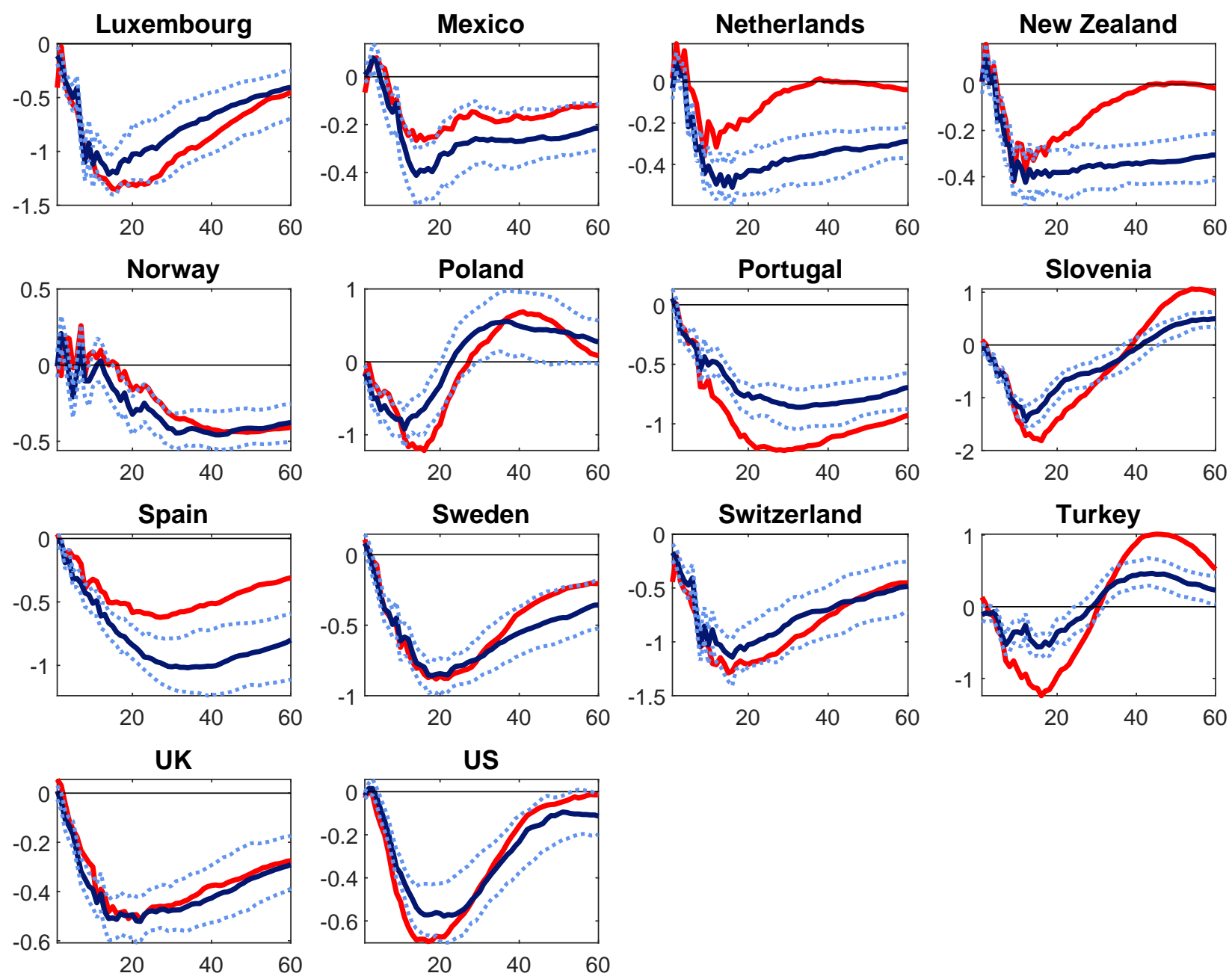

Equal-weighted

Trade-weighted 
Figure 7: Sectoral Spillover of Global REU
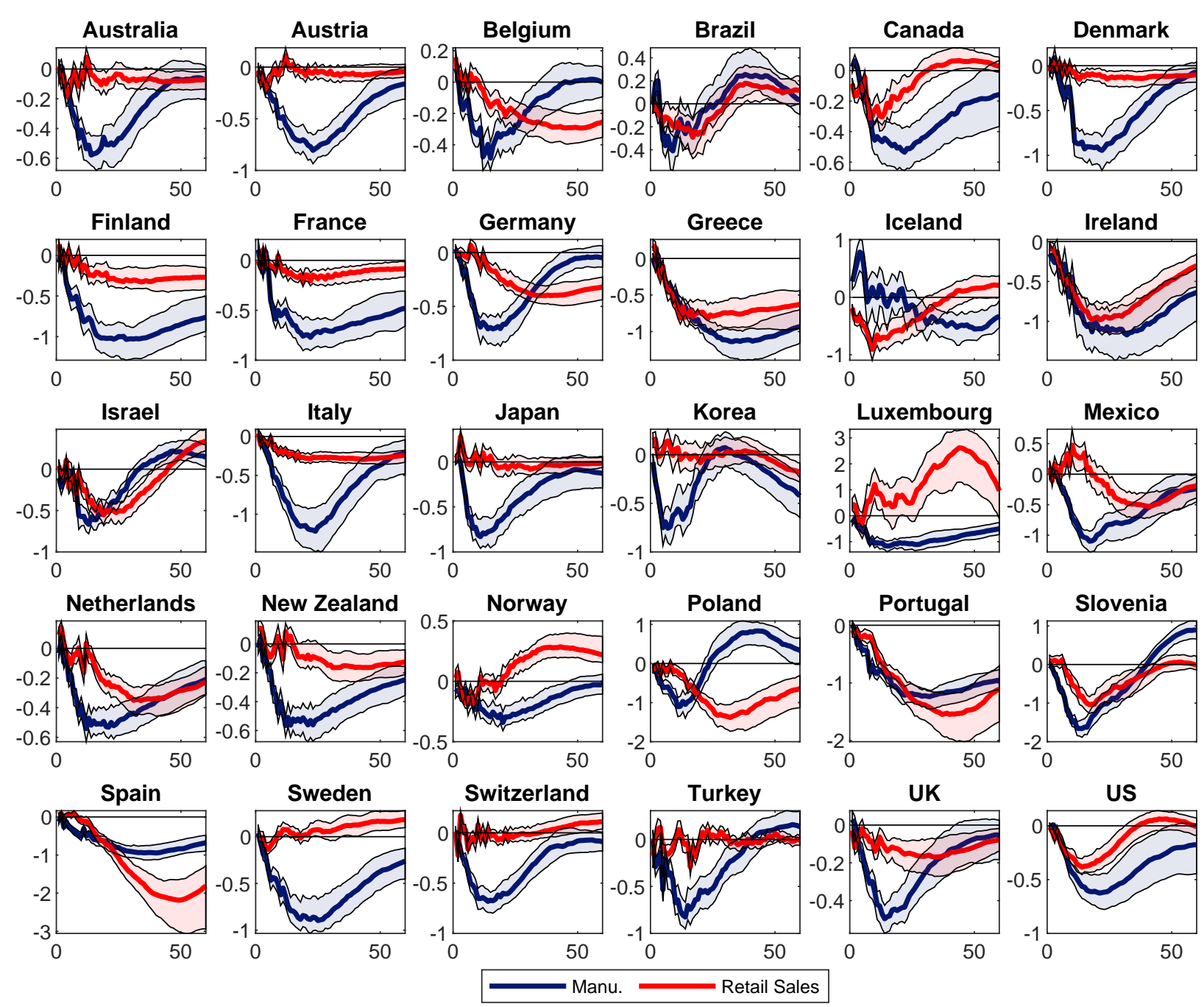

The figure shows median impulse-response functions and their 68 percent confidence intervals for the effect of a our measure of foreign REU, which is calculated as the trade-weighted average of the REU time series for all other countries (see Equation (11) ) on (domestic) manufacturing production (in blue) and retail sales (in red) for all countries in our sample. The VAR setting is explained in section 3.2 